\title{
Composition and potential grazing impact of salp assemblages off Baja California during the 1997-1999 El Niño and La Niña
}

\author{
Clara M. Hereu ${ }^{1, *}$, Bertha E. Lavaniegos ${ }^{1,2}{ }^{,}$Gilberto Gaxiola-Castro ${ }^{1}$, \\ Mark D. Ohman' \\ ${ }^{1}$ Departamento de Oceanografía Biológica, Centro de Investigación Científica y Educación Superior de Ensenada, \\ km 107 Carretera Tijuana-Ensenada, 22860 Ensenada, Baja California, Mexico \\ ${ }^{2}$ Integrative Oceanography Division, Scripps Institution of Oceanography, University of California, San Diego, La Jolla, \\ California 92093-0218, USA
}

\begin{abstract}
Salps off Baja California (BC) showed substantial changes during El Niño of 1997-1998 and La Niña of 1998-1999. Salps were particularly abundant during the warm phase and showed a decreasing trend after the transition to cool conditions (October 1998). Salp swarms (>1 salp $\mathrm{m}^{-3}$ ) were present throughout the study period, with the exception of October 1999 and October 2000. They appeared more frequently S of Punta Baja $\left(30^{\circ} \mathrm{N}\right)$. The most abundant species was Thalia orientalis followed by Salpa fusiformis. T. orientalis decreased in abundance from winter 1998 to autumn 1999, while $S$. fusiformis showed a strong increase during the development and establishment of La Niña (autumn 1998 and winter 1999). Other species (T. rhomboides, T. cicar, Cyclosalpa strongylenteron, C. polae, S. cylindrica and Ritteriella amboinensis) associated with warmer waters were present off the southernmost part of the BC peninsula. They were probably advected into the area from the SSW by an intensified coastal poleward jet that characterized the El Niño peak in the area. Estimates of carbon ingestion from daily rations of Thalia spp. and S. fusiformis indicated that swarms required from $<1$ to $>100 \%$ of the daily primary production and phytoplankton biomass. Fecal pellet production of swarms of these species was estimated at between $<1$ and $609 \mathrm{mg} \mathrm{C} \mathrm{m}^{-2} \mathrm{~d}^{-1}$. Considering that size and sinking rates of fecal pellets are related to salp body size, the swarms of Thalia and $S$. fusiformis may have had a differential impact on the pelagic ecosystem in terms of recycling and vertical transport of biogenic material through the water column.
\end{abstract}

KEY WORDS: Salps · El Niño · La Niña · California Current · Baja California · Grazing impact Resale or republication not permitted without written consent of the publisher

\section{INTRODUCTION}

El Niño is the dominant source of interannual variability in many parts of the world's oceans, producing a significant impact on pelagic ecosystems. The anomalous physical and biological conditions along the California Current System (CCS) from 1997 through to the end of 2000 were associated with one of the strongest El Niño Southern Oscillation (ENSO) events of the last century (Durazo \& Baumgartner 2002, Lynn \& Bograd 2002). The oceanographic evolution of El Niño 1997-1998 included an eastward propagation of high sea level and depressed isotherm anomalies along the equator beginning in early 1997, reaching the W coast of the Americas by mid-1997 (Strub \& James 2002). Off Baja California (BC) anomalous poleward transport was recorded from May 1997 through January 1998 (Strub \& James 2002). Water mass anomalies registered during the warm phase of the ENSO off BC were the result of intrusion of water from the $\mathrm{W}$ and the strengthening and broadening of the poleward nearshore flow within the CCS (Durazo \& Baumgartner 2002, Lynn \& Bograd 2002).

Changes in water mass characteristics and circulation resulted in changes in biomass as well as in plank- 
ton community structure. The most obvious effect of El Niño 1997-1998 on primary producers was observed at distances of over $100 \mathrm{~km}$ offshore; phytoplankton biomass assessed by remote sensing was reduced by $30 \%$ off Southern California, while it increased by $40 \%$ off BC (Kahru \& Mitchell 2000). While chlorophyll biomass was low from the Gulf of Alaska to Central California (Bograd \& Lynn 2001, Chavez et al. 2002), nearly normal values were observed off Southern California and in BC coastal and oceanic waters (Kahru \& Mitchell 2000, Bograd \& Lynn 2001, Lavaniegos et al. 2002). Zooplankton biomass was also diminished in northern regions (Mackas \& Galbraith 2002, Lavaniegos \& Ohman 2003), while it was similar to historical values off BC (Lavaniegos et al. 2002).

Shifts in the geographic boundaries of several zooplankton species due to changes in latitudinal transport have also been observed in response to changing conditions induced by El Niño (Mackas \& Galbraith 2002, Peterson et al. 2002, Lavaniegos \& Ohman 2003, Jimenez-Pérez \& Lavaniegos 2004). Species richness of euphausiids and copepods increased during the warm phase of the ENSO cycle in several regions of the CCS due to the intrusion of species with affinity to higher temperatures into an area where they are normally excluded (Mackas \& Galbraith 2002, Peterson et al. 2002, Jimenez-Pérez \& Lavaniegos 2004, Linacre 2005). Shifts in the zooplankton size spectrum towards smaller-sized animals have also been related to El Niño 1997-98 (González et al. 2000a,b, Hopcroft et al. 2002, Lavaniegos et al. 2002, Jimenez-Pérez \& Lavaniegos 2004).

Among gelatinous taxa, salps have shown variable responses during different El Niño events. In a long term study in the Southern California region, salps comprised one of the most abundant groups in some events (e.g. El Niño 1982-83) but they were in moderate abundance or almost absent in others (e.g. El Niño 1958-59 and 1997-98, respectively) (Lavaniegos \& Ohman 2003). A remarkable characteristic of salps is their ability to reproduce quickly under favorable conditions and form dense swarms which can extend thousands of kilometers and persist for several months (Andersen 1998). As salp swarms develop, they can potentially graze the entire daily primary production and potentially exclude other species that use the same food resource, such as pelagic crustaceans and fish larvae. This can have important implications in upwelling areas if carbon flows mainly through the mesozooplankton, and organisms such as copepods and euphausiids are the main links between primary production and fish production. In meso and oligotrophic waters dominated by microbial food webs (Fortier et al. 1994) salps may shortcut the traditional food chain and transfer part of the pico and nanoplank- ton biomass directly to higher trophic levels while part of the production is transferred as fast-sinking aggregates to deeper layers or to the benthos. Thus, the distribution and abundance of salps as primary consumers has important implications relative to other zooplankton in the cycling of chemical elements, nutrients and energy flow in the pelagic environment and the flux of particles out of the euphotic zone (Michaels \& Silver 1988, Fortier et al. 1994, Landry et al. 1994, Andersen 1998).

In October 1997 the IMECOCAL (Investigaciones Mexicanas de la Corriente de California) program reestablished the sampling grid previously surveyed by the California Cooperative Oceanic Fisheries Investigations (CalCOFI) program off the BC peninsula between 1949 and the early 1980's. The main goal of IMECOCAL is to provide information on the role of physical processes on the biological components of the pelagic ecosystem in the southernmost region of the CCS. Prior to the present study, total salp abundance was reported as part of the changes in functional groups during 1997-1998 off BC (Lavaniegos et al. 2002). In this work we analyze changes in species composition of the salp assemblage during the period 1997 to 2000 in order to asses the effects of El Niño 1997-1998 and La Niña 1998-1999 on patterns of distribution and the potential grazing impact of these pelagic tunicates.

\section{MATERIALS AND METHODS}

Study area. The CCS comprises a system of currents along the $\mathrm{W}$ coast of North America with strong interannual and seasonal scale variability. There are 3 major currents embedded within the CCS: the equatorward California Current (CC), the sub-surface poleward California Undercurrent (CU) and the poleward coastal countercurrent (referred to as the Davidson Current $\mathrm{N}$ of Pt. Conception) flowing close to the shore, mainly between October and February (Hickey 1979). The dominant scales and dynamics of the circulation over much of the CCS are established mainly by strong alongshore winds. Coastal upwelling is particularly intense in spring and summer (Huyer 1983), promoting high primary production. The present study embraces the southernmost part of the CCS (off BC), a region with conditions highly variable due to the onshore movement of offshore eddies and wind-forced equatorward surface currents (Lynn \& Simpson 1987). The winds are upwelling — favorable year round, but maximal in spring (Huyer 1983). Plankton species are a mixture of endemic transition zone, northern subarctic species, and equatorial and tropical organisms from the SSW. 
Sampling. The sampling grid during IMECOCAL cruises consisted of stations in linear transects perpendicular to the coast, corresponding to CalCOFI Lines 100 through 137 (Fig. 1). The distance between stations is $37 \mathrm{~km}$ and between lines, $74 \mathrm{~km}$. In the present study, we selected alternate stations on each line for sampling in order to ensure that there was an equal distance between the sampling stations. From 1997 to 2000, 11 cruises were conducted on the R/V 'Francisco de Ulloa' and 1 on the R/V 'El Puma'. These were all given 4-digit numbers, the first 2 digits designating the year and the last 2 the month. Cruise 9710 comprised only stations from Lines 110 to 127. A few stations from other cruises were not sampled because of weather conditions at sea.

At each station, conductivity, temperature and pressure (CTD)/rosette casts were carried out to a depth of $1000 \mathrm{~m}$. Water samples were collected at selected depths $(0,10,20,50,100$, and $150 \mathrm{~m})$ in Niskin bottles. One or $2 \mathrm{l}$ were filtered through glass fibre filters (GF/F) (nominally $0.7 \mu \mathrm{m}$ pore size) and the filter frozen for further analysis of chlorophyll $a$ in the laboratory. Primary productivity in situ experiments using the uptake of radioactive carbon incubations were performed at selected stations.

Zooplankton tows were performed with a bongo net (61 $\mathrm{cm}$ diameter, $505 \mu \mathrm{m}$ mesh). The net was towed from $210 \mathrm{~m}$ to the surface, and at shallower stations from $10 \mathrm{~m}$ above the bottom to the surface. The volume of filtered water during the tow was measured with a flowmeter in the mouth of the net. Samples were preserved in a $4 \%$ formaldehyde solution neutralized with sodium borate.

Laboratory. Chlorophyll a was extracted in $90 \%$ acetone over $24 \mathrm{~h}$ at $4^{\circ} \mathrm{C}$ by the Holm Hansen method modified by Venrick \& Hayward (1984) and measured with a Turner Designs (10-05R) fluorometer. Primary productivity data for cruises 9807 and 9810 were taken from Aguirre-Hernández et al. (2004) and for cruises in 1999 from Sosa-Ávalos (2002). Macrozooplankton biomass was determined by the displacement volume method.

In 314 samples from 9 cruises $(9710,9801,9807$, 9810, 9901, 9904, 9907, 9910, 0010), salps were identified to species either in the whole sample or, in cases of high abundance in a subsample consisting of between 1/16 and 1/2 of the total, until at least 400 ind. of the most abundant species had been analyzed. The rest of the sample was also analyzed for rare or less common species. For an additional 122 samples from cruises 0001, 0004 and 0007, total numbers of salps were counted using 1/8 of each sample. The primary sources for the identification of salps were Yount (1954), Van Soest (1972) and Godeaux (1998).

Approximately $15 \%$ of the samples from cruises 9801 , 9807, 9810, 9901, 9904 and 9908 were selected to measure total length of Salpa fusiformis and Thalia spp. zooids. The selection of samples depended on the abundance and/or availability of primary productivity data. A subsample of about 60 to 100 zooids of each generation (aggregate and solitary) was measured to the nearest $\mathrm{mm}$. The measurements in the subsample were extrapolated to the total sample and to other neighboring stations where these species were present in high abundance (i.e. when both summed more than 250 salps $\mathrm{m}^{-2}$ ). For Cruise 9904 and 9908 we made estimates for 2 additional stations where Thalia abundance surpassed 100 salps $\mathrm{m}^{-2}$.

No correction for changes in length of specimens in preservative was applied, though some shrinkage of $10 \%$ or less exists for Thalia democratica (Heron et al. 1988, Nishikawa \& Terazaki 1996) and of $20 \%$ for Salpa fusiformis (Madin et al. 1981) preserved in formaldehyde.

Data analysis. To illustrate climate evolution from 1997 to 2000 and to highlight interannual rather than seasonal variability, temperature and salinity anomalies at $10 \mathrm{~m}$ depth were calculated. For this purpose, in each station along Lines 110 and 120, the seasonal mean from CalCOFI data for the period 1950-1978 (Lynn et 
al. 1982) was removed from the results for each IMECOCAL cruise. To approximate column water stratification, the density gradient between 10 and $100 \mathrm{~m}$ was used, as were the anomalies remaining after subtracting the 1950-1978 mean density gradient. The earlier time period was selected for a baseline because it provided sufficient seasonal and interannual coverage.

Monthly Coastal Upwelling Index (CUI) anomalies were obtained from the Pacific Fisheries Environmental Laboratory (PFEL) at www.pfel.noaa.gov. The index is based on estimated offshore Ekman transport driven by geostrophic wind stress, which is derived from 6-hourly synoptic and monthly mean surface atmospheric pressure fields. The magnitude of the offshore component of Ekman transports is considered to be an index of the amount of water upwelled from the base of the Ekman layer. Positive values are, in general, the result of equatorward wind stress. Negative values imply downwelling, the onshore advection of surface waters accompanied by a downward displacement of water. In this study CUI anomalies are presented for the period 1997-2000 in the 2 locations within the IMECOCAL: western Punta Eugenia $\left(27^{\circ} \mathrm{N}, 116^{\circ} \mathrm{W}\right)$ and western Guadalupe Island $\left(30^{\circ} \mathrm{N}, 119^{\circ} \mathrm{W}\right)$ (Fig. 1).

Salp abundance is expressed per $\mathrm{m}^{3}$, or $\mathrm{m}^{2}$ after correction for tow depth. Prior to estimating mean abundance, data were log-transformed $(\log x+1)$. Statistical comparisons between cruises were performerd using the non-parametric Kruskal-Wallis test, since after log transformation of data, homoscedasticity was not attained. After detection of significant differences among cruises corresponding to the same season, pair-wise comparisons were performed using the Mann-Whitney $U$-test. Both day and night samples were enumerated and analysis was performed with no distinction between the 2 types of sample, since no significant day-night differences were found in total abundance $(p=0.41)$. Spearman rank order correlation was performed between salp abundance and environmental variables: $10 \mathrm{~m}$ temperature and salinity, density gradient (10 to $100 \mathrm{~m}$ ), and surface and integrated ( 0 to $150 \mathrm{~m}$ ) chlorophyll a biomass.

Although grazing determinations could not be carried out directly at sea, 2 indirect approaches were used to estimate the proportion of primary production (PP) and chlorophyll standing stock ingested by salps. In Method (1) maximum daily carbon consumption was approximated from salp biomass and reported values of weight-specific C ration for salps fed under favorable conditions in the laboratory (Deibel 1982, Andersen 1985). Length measurements were converted to carbon content (Table 1); salp C biomass was then integrated vertically between 0 and $200 \mathrm{~m}$ depth, and finally $\mathrm{C}$ biomass was multiplied by weight-specific daily carbon ration (Table 1) to estimate carbon con- sumption. Carbon consumption was then compared with daily water-column primary production integrated over the euphotic layer $(\sim 80 \mathrm{~m})$ and with integrated chlorophyll a (0 to $150 \mathrm{~m}$ ) previously converted to carbon units using a $\mathrm{C}$ :Chl ratio of 50:1 (Eppley 1968). The results were expressed as the percentage of carbon required to sustain salp population biomass. For several stations with high abundance of salps but without measures of primary productivity, the missing values were interpolated from the nearest PP station value. In Method (2) daily clearance rate as a function of salp length for the appropriate aggregate and solitary zooid generations (Table 1) was multiplied by the number of zooids in each length class to estimate the water filtered by the salp population collected in a tow. This value divided by the volume of water filtered during sampling tow gives the proportion of water filtered by the population $\mathrm{d}^{-1}$. This proportion was then multiplied by the chlorophyll biomass (in carbon units) to calculate the amount consumed by salps at each station.

Mean defecation rate for Salpa fusiformis (12.4 $\mathrm{\mu g}$ $\mathrm{C}$ mg body $\mathrm{C}^{-1} \mathrm{~h}^{-1}$ ) estimated by Small et al. (1983) was applied in this study to estimate daily fecal carbon flux resulting from swarms of this species. No estimates of defecation rate exist for Thalia democratica, but rates for other species range from 10 to $30 \%$ in terms of body weight (Andersen 1998). We applied the lowest value to Thalia swarms in our study.

\section{RESULTS}

\section{Water-column properties}

Temperature anomalies at $10 \mathrm{~m}$ depth ranged from $6^{\circ} \mathrm{C}$ in October 1997 to $-1^{\circ} \mathrm{C}$ in April 1999, these months being the culmination of El Niño 1997-1998

Table 1. Salpa fusiformis and Thalia democratica. Regressions used to estimate carbon content $(\mathrm{C}[\mathrm{mg}])$, and clearance rate $\left(\mathrm{C}_{\mathrm{R}}\left[\mathrm{ml}\right.\right.$ ind..$\left.\left.^{-1} \mathrm{~h}^{-1}\right]\right)$ as a function of total length $(L[\mathrm{~mm}])$ for the aggregate and solitary generations, and daily specific carbon ration $\left(D_{R}\left[\mu g C\right.\right.$ ingested per $\mu g$ salp $\left.\left.C d^{-1}\right]\right)$ used to estimate grazing impact

\begin{tabular}{|c|c|c|c|}
\hline Function & Aggregate & Solitary & Source \\
\hline \multicolumn{4}{|c|}{ T. democratica } \\
\hline $\mathrm{C}$ & $0.0014(L)^{2.04}$ & $0.0029(L)^{1.59}$ & Heron et al. (1988) \\
\hline $\mathrm{D}_{\mathrm{R}}$ & 0.59 & 0.59 & Deibel (1982) \\
\hline $\mathrm{C}_{\mathrm{R}}$ & $0.0726(L)^{2.83}$ & $0.0726(L)^{2.83}$ & Mullin (1983) \\
\hline \multicolumn{4}{|c|}{ S. fusiformis } \\
\hline $\mathrm{C}$ & $0.0005(L)^{2.78}$ & $0.0014(L)^{2.05}$ & Cetta et al. (1986) \\
\hline $\mathrm{D}_{\mathrm{R}}$ & 1.07 & 1.17 & Andersen (1985) \\
\hline $\mathrm{C}_{\mathrm{R}}$ & $0.0145(L)^{3.32}$ & $0.162(L)^{2.27}$ & Andersen (1985) \\
\hline
\end{tabular}



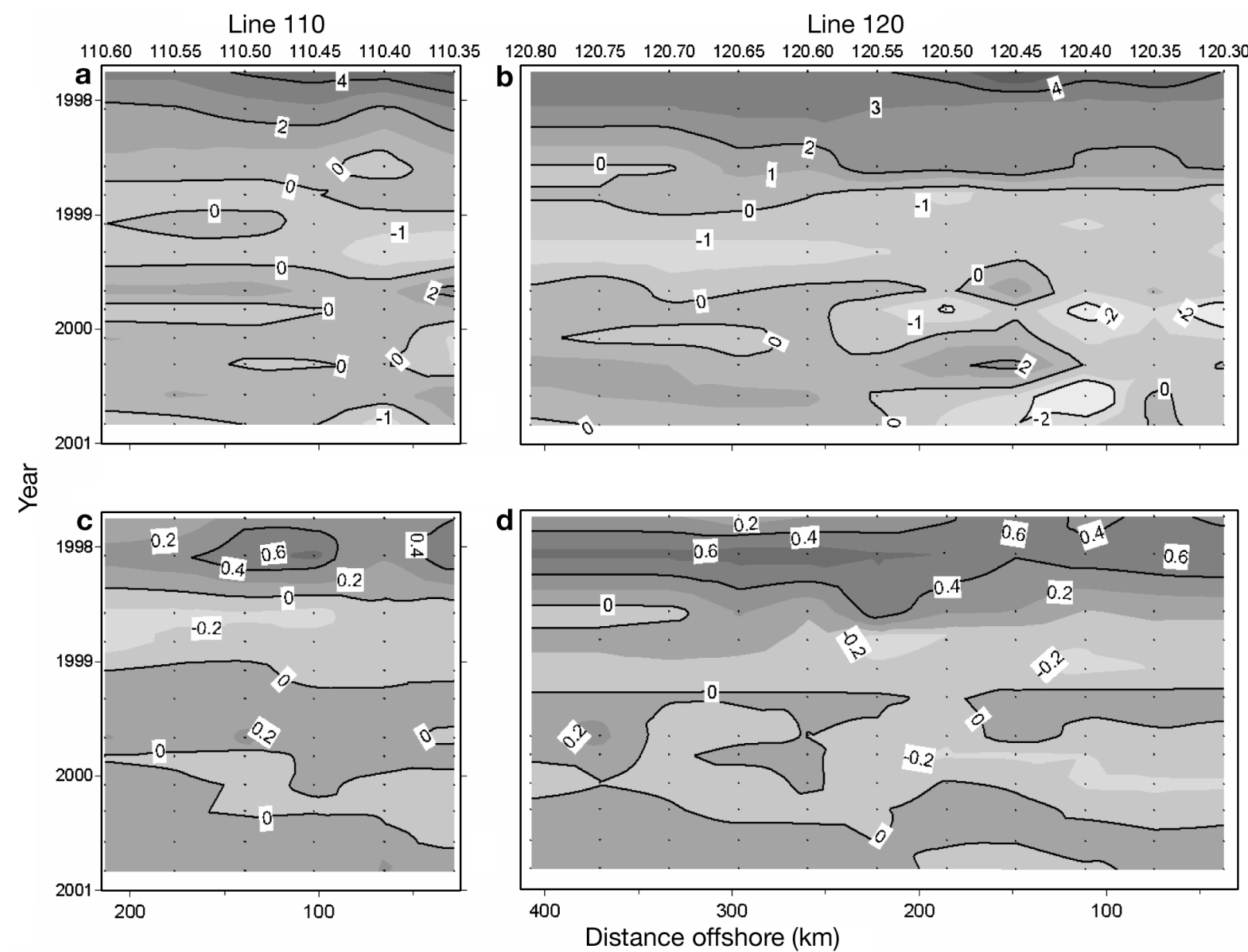

Fig. 2. Time-distance offshore plots of $(\mathrm{a}, \mathrm{b})$ temperature $\left({ }^{\circ} \mathrm{C}\right)$ and $(\mathrm{c}, \mathrm{d})$ salinity anomalies at a depth of $10 \mathrm{~m}$ for stations along Lines $(\mathrm{a}, \mathrm{c}) 110$ and $(\mathrm{b}, \mathrm{d}) 120$. For position of lines see Fig. 1 . Anomalies estimated by $X_{i}-X_{\text {, where }} X_{i}$ is the value measured during 1 IMECOCAL cruise and $X$ is the seasonal mean for the period 1950-1978

and La Niña 1998-1999 in the region (Fig. 2a,b). After the intense warming, the change to cool conditions started in the $\mathrm{S}$, since at Line 120 negative anomalies were observed from October 1998 (Fig. 2b). By 2000 the system returned to normal conditions, but negative anomalies persisted toward the coast along Line 120, corresponding to the shallow stations of Vizcaino Bay (Fig. 2b).

Positive anomalies of salinity (up to 0.6) corresponded with positive anomalies of temperature, indicating the influence of subtropical water during El Niño (Fig. 2c,d). Further, the presence of negative salinity anomalies offshore (Fig. 2c) or zero anomalies (Fig. 2d), indicated the influence of low salinity water, suggesting that El Niño conditions may have subsided from July 1998 onwards. During the last part of 1999 and through 2000 salinity anomalies in the region were close to zero, with some filaments around -0.2 apparent only in Line 120.

Water-column stratification, described here as density gradient, showed seasonal changes, with the high- est gradient occurring in autumn and the lowest in spring (Fig. 3a,b). Latitudinal differences were also evident, as during autumn the density gradients reached around $2.4 \mathrm{~kg} \mathrm{~m}^{-3}$ at Line 120 (Fig. 3b), while it was $2.0 \mathrm{~kg} \mathrm{~m}^{-3}$ at Line 110 (Fig. 3a). However, on both lines the maximal gradient was found during the peak of El Niño, in autumn 1997. Those density gradients represented positive anomalies of up to $0.8 \mathrm{~kg} \mathrm{~m}^{-3}$ (Fig. 3c,d). In contrast, negative anomalies occurred during La Niña 1998-1999. Stratification in 2000 was close to normal conditions in Line 110, but Line 120 showed positive anomalies.

El Niño was characterized by unusually weak upwelling in northern BC from mid-1997 to September 1998, while nearly normal values persisted in central BC (Fig. 4). Upwelling anomalies remained positive from October 1998 in northern Baja (from September in central BC) until late 1999, indicating a prolonged La Niña influence in the region. During 2000 we observed the usual spring-summer season of intense upwelling followed by a weak autumn-winter season. 

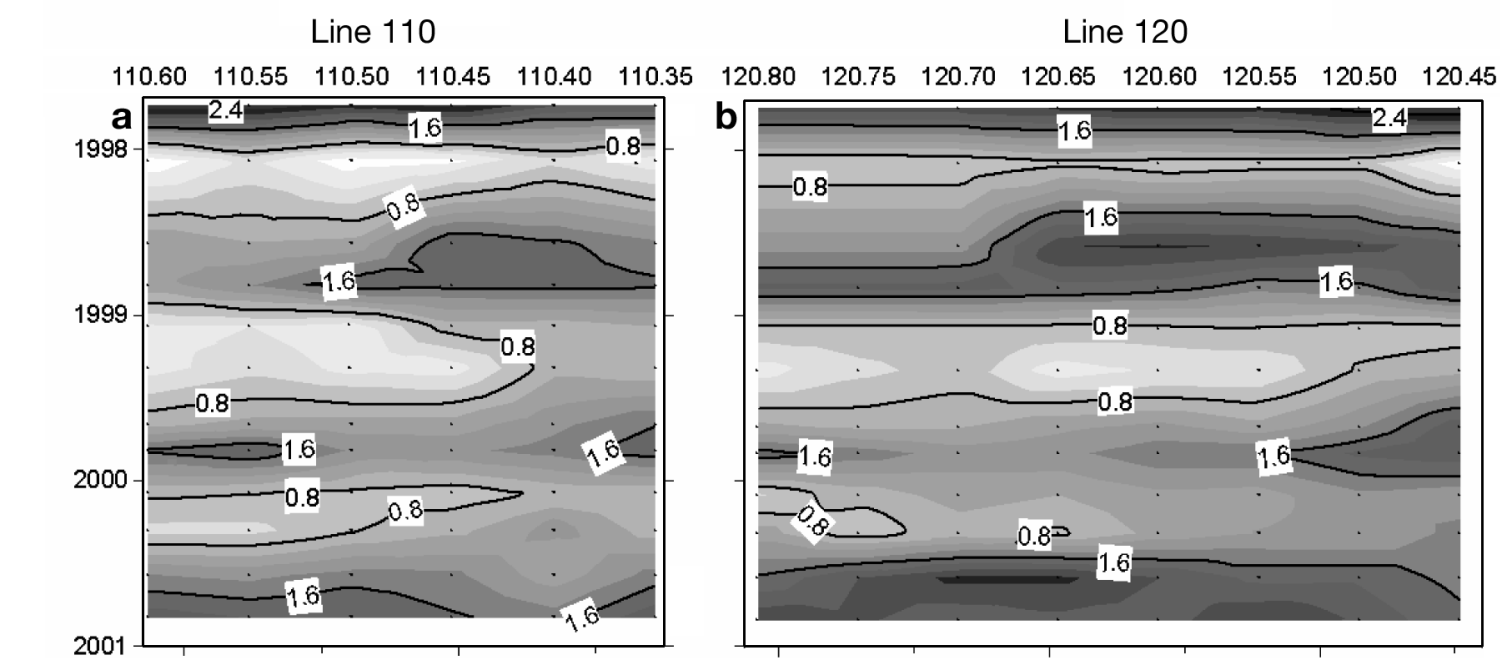

ঠัญ
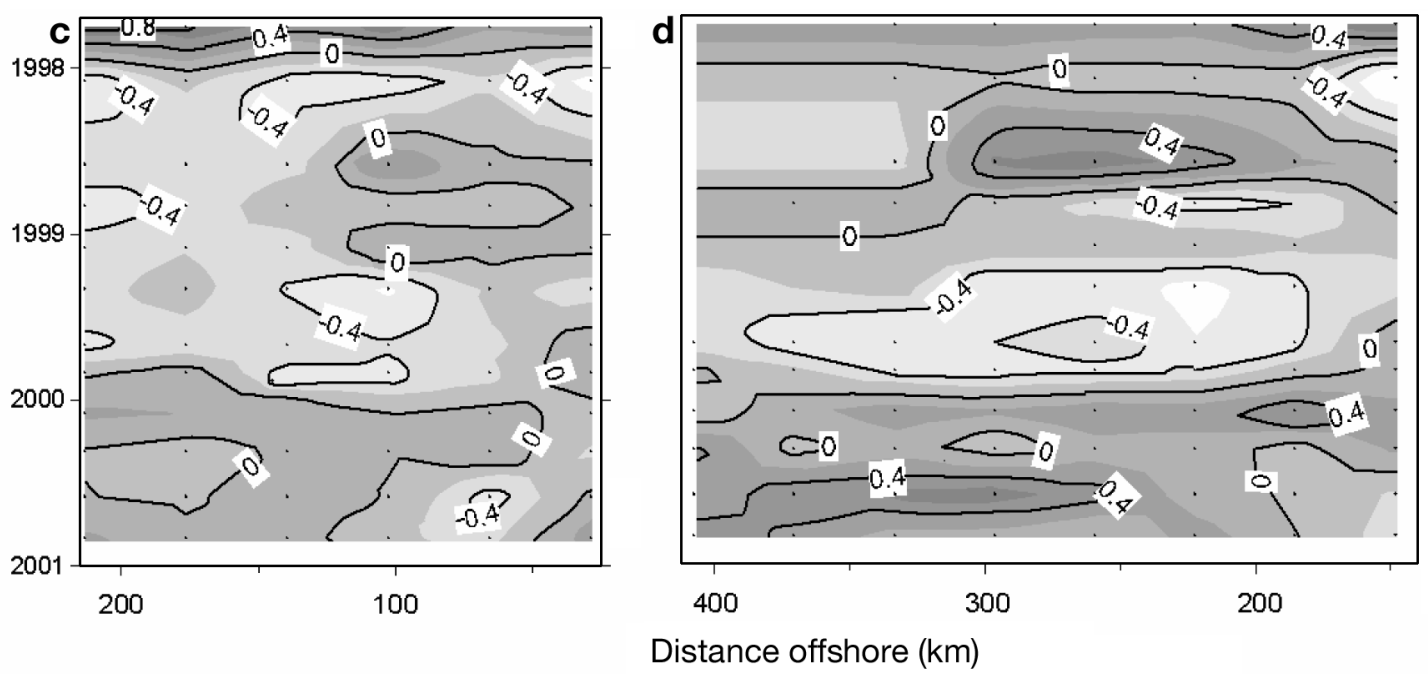

Fig. 3. Time-distance offshore plots of $(\mathrm{a}, \mathrm{b})$ density difference $\left(\mathrm{kg} \mathrm{m}^{-3}\right)$ between depths of 100 and $10 \mathrm{~m}$ and $(\mathrm{c}, \mathrm{d})$ density difference anomalies for stations along Lines $(\mathrm{a}, \mathrm{c}) 110$ and $(\mathrm{b}, \mathrm{d}) 120$. For position of lines see Fig. 1. Anomalies estimated by $X_{i}-X_{,}$ where $X_{i}$ is the value measured during 1 IMECOCAL cruise and $X$ is the seasonal mean for the period 1950-1978

However, negative upwelling anomalies during May and June at both locations indicated a slightly weaker than usual upwelling season.

\section{Chlorophyll $a$ and primary production}

Mean surface chl a through the study period showed seasonal differences, peaking in April of both 1999 and 2000 (Fig. 5). In spring high spatial variability was also

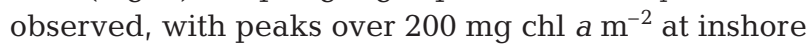
stations in Punta Baja and Vizcaino Bay on April 1999 and at most of the coastal stations on April 2000. Unfortunately we did not have data for April 1998, when El Niño was taking place. Only for July 1998 were values lower than at corresponding periods in 1999 and 2000.
A tendency toward lower mean integrated chl $a$ in the $\mathrm{N}$ region (Lines 100 to 110 ) than the central region (Lines 113 to 137) appeared during 1999 and 2000, though differences were not significant. The integrated chlorophyll in the central region during 1999 and 2000 was around 16 and $23 \%$ higher than in 1998, respectively, with the exception of January.

Euphotic zone integrated primary production (PP) ranged from 88 to $2646 \mathrm{mg} \mathrm{C} \mathrm{m}^{-2} \mathrm{~d}^{-1}$ throughout the study period. During 1998, the cruise mean integrated PP was slightly higher in July $\left(594 \pm 283 \mathrm{mg} \mathrm{C} \mathrm{m}^{-2} \mathrm{~d}^{-1}\right.$, $\mathrm{n}=10$ ) than in October ( $366 \pm 80 \mathrm{mg} \mathrm{C} \mathrm{m}^{-2} \mathrm{~d}^{-1}, \mathrm{n}=12$ ). The opposite occurred in 1999, when in October PP was $1262 \pm 380 \mathrm{mg} \mathrm{C} \mathrm{m}^{-2} \mathrm{~d}^{-1}(\mathrm{n}=15)$, while in April and August PP values were lower $(828 \pm 535$ [n = 8] and $717 \pm 121 \mathrm{mg} \mathrm{C} \mathrm{m}^{-2} \mathrm{~d}^{-1}[\mathrm{n}=12]$, respectively). In 


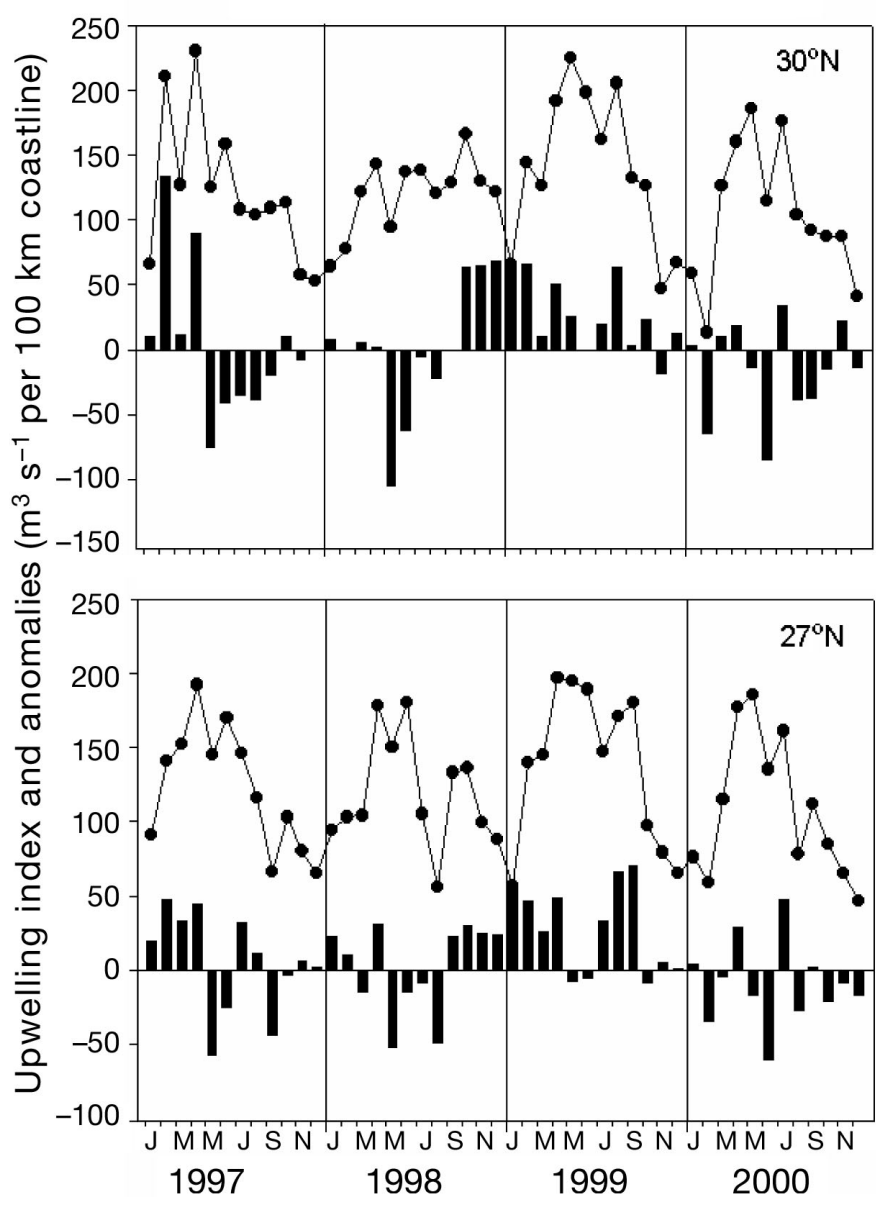

Fig. 4. Monthly upwelling index (line) and upwelling index anomalies (bars) after removing the mean for the period 1946-2003, in 2 sites off Baja California (BC): northwestern Guadalupe Island $\left(30^{\circ} \mathrm{N}, 119^{\circ} \mathrm{W}\right)$ and western Punta Eugenia $\left(27^{\circ} \mathrm{N}, 116^{\circ} \mathrm{W}\right)$. Data from the Pacific Fisheries Environmental Laboratory, available at www.pfel.noaa.gov

general, high PP corresponded to higher chlorophyll biomass at coastal stations (Spearman $\mathrm{R}=0.5$, p < $0.0001, \mathrm{n}=56$ ).

Zooplankton biomass remained high through 1998 in central Baja, while in northern Baja it gradually decreased after autumn 1997 (Fig. 5c). During La Niña winter of 1999 a strong decrease in biomass was observed in the central region, reaching the lower levels of the northern region. Afterward, the zooplankton biomass of both regions progressed together, showing a recovery beginning in April 2000.

\section{Salp abundance and species composition}

Salps were present in all cruises from October 1997 to October 2000 (Fig. 6). The most pronounced temporal change was the high abundance during the warm phase of the ENSO followed by a remarkable decrease after October 1998 (Figs. 5 \& 6). Swarm densities ( $>1$ salp $\mathrm{m}^{-3}$ ) were observed in $>40 \%$ of the stations through 1998 compared to $<30 \%$ of the stations in the 1999 and 2000 cruises. The swarms occurred mainly in the central $\mathrm{BC}$ region (Fig. 6), while the northern area showed a low incidence of salps with only an episode of increase in January 1999, attributable to swarms of Salpa fusiformis (Fig. 7). Seasonal differences were observed during 1999 and 2000. Salps were scarcely present in autumn of La Niña and during summer and autumn 2000.

A total of 25 species was recorded (Table 2). The most abundant species were Thalia orientalis, T. democratica and Salpa fusiformis. Thalia spp. were abundant during El Niño, decreasing from January 1998 to a minimum in October 1999. The decreasing trend in abundance began earlier in the northern region than in the central region (Figs. $7 \& 8$ ). $S$. fusiformis was also abundant during the warm period but peaked during transition conditions (Cruises 9810 and 9901) and virtually disappeared afterwards (Figs. 7 \& 9). The species reappeared in southern stations in October 2000.

The highest salp species richness was observed during the peak of El Niño (January 1998), whereas the lowest occurred in spring and summer of La Niña (Table 2). Although Cruise 9710 covered a smaller area and the total abundance was not particularly high (Fig. 6), the number of species recorded was similar to the other October cruises that covered a more extensive area.

The only species occurring throughout the study period were Thalia orientalis and T. democratica. The dominance of $T$. orientalis species was $>50 \%$ of total salps between October 1997 and July 1998. Swarms of this species occurred in the central region (Fig. 10), reaching an abundance of 1471 ind. $1000 \mathrm{~m}^{-3}$ (antilogged mean). T. democratica was the second most abundant species of the genus to occur in both regions; peaks of this species were recorded in October 1998 and again in October 2000 (Fig. 10). Proliferations of $T$. rhomboides were important only on cruise 9801. T. cicar, was present throughout El Niño and the transition to La Niña in low abundance, but disappeared in the cool period (Fig. 10).

The most striking differences in species composition and abundance were observed in April 1999, when low abundance of Thalia orientalis and T. democratica was observed in $70 \%$ of the stations and only 3 other species were recorded at 1 or 2 stations.

Total salp abundance was positively correlated with temperature and salinity at $10 \mathrm{~m}$ depth (Table 3 ). Positive correlations with these variables were also observed when only the abundance of Thalia spp. was 

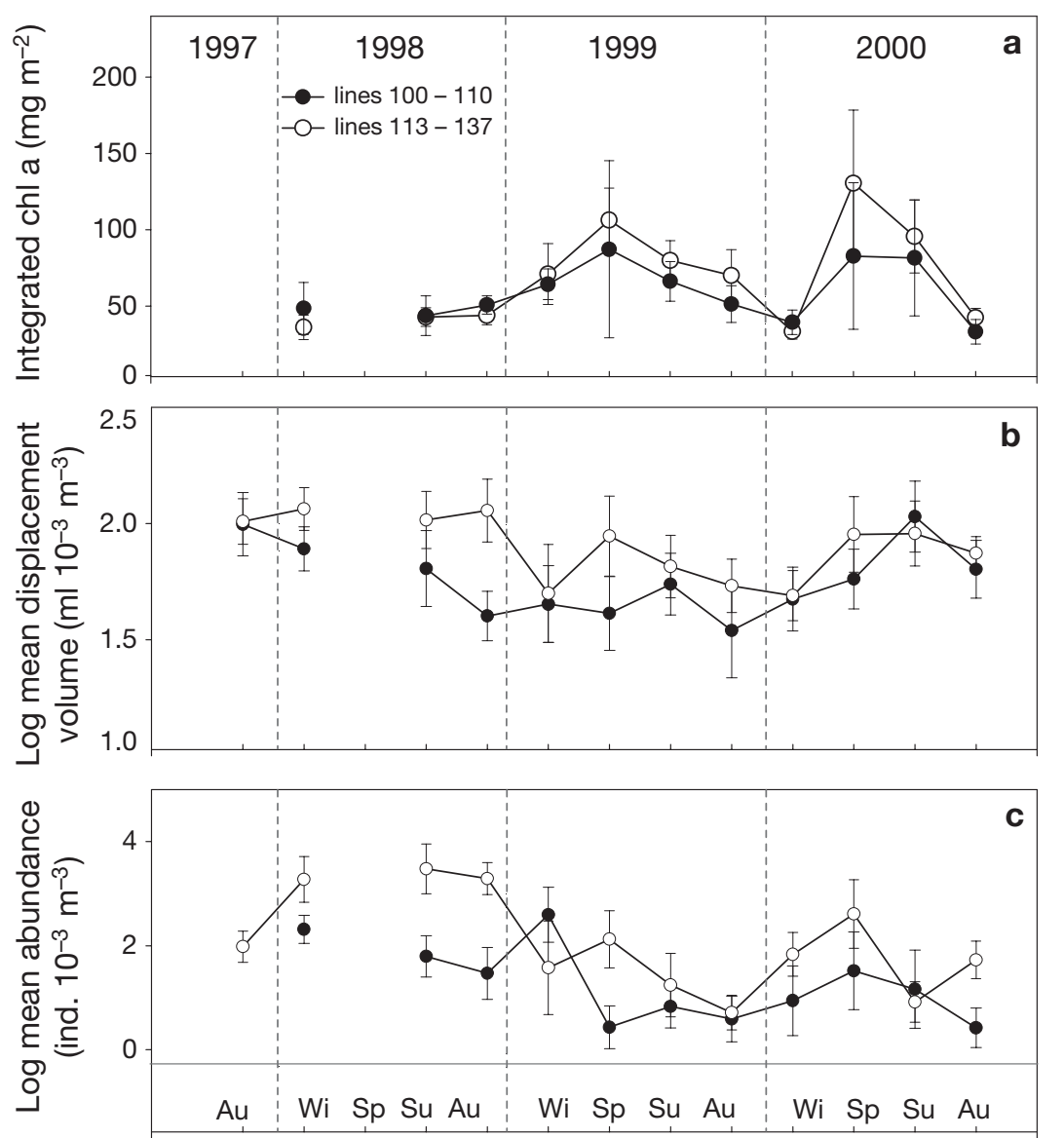

Fig. 5. Regional mean and 95\% confidence interval of (a) integrated chlorophyll a (0 to $150 \mathrm{~m}$ depth), (b) zooplankton displacement volume, and (c) total salp abundance $( \pm \mathrm{CI})$ for northern $\mathrm{BC}$ area (Lines 100 to 110$)$ and central $\mathrm{BC}$ area (Lines 113 to 137). Zooplankton displacement volume and salp abundances were $\log (x+1)$ transformed. Au: autumn; Wi: winter; Sp: spring; Su: summer

considered. A similar result for Salpa fusiformis was found if $\alpha$ is taken at $5 \%$. However, the correlation with temperature was not significant when corrected for multiple comparisons by the Bonferroni criterion ( $\alpha=0.01$ ). The correlation between density gradient in the upper $100 \mathrm{~m}$ and total salps abundance was weakly negative at $\alpha=0.02$. No correlation was found with surface chlorophyll, while the correlation was negative with integrated chlorophyll, if $\alpha$ of 0.05 is considered. The negative correlation with integrated chlorophyll is consistent with $\alpha$ taken at 0.01 only for Thalia spp. (Table 3).

\section{Grazing impact}

The estimated grazing impact of Thalia spp. and Salpa fusiformis was particularly high in the central part of BC (Method 1, Table 4). The only important swarms in the northern region were observed in Janu- ary 1999 when $S$. fusiformis biomass was between 56 and $693 \mathrm{mg} \mathrm{C} \mathrm{m}^{-2}$. We do not have primary production data for that particular cruise, but by approximating carbon availability from chlorophyll biomass, we were able to estimate carbon ingestion from daily ration (Method 1) of these salps at up to $30 \% \mathrm{~d}^{-1}$ of phytoplankton standing stock.

In the central region, the highest abundance of Thalia spp. occurred during El Niño, (Fig. 8) with a peak in July 1998 (42330 ind $\mathrm{m}^{-2}$ ) corresponding to maximum biomass (861 $\mathrm{mg} \mathrm{C} \mathrm{m}^{-2}$ ) (Table 4). Based on daily ration, Thalia spp. had an average estimated carbon consumption of 40 and $80 \mathrm{mg} \mathrm{C} \mathrm{m}^{-2} \mathrm{~d}^{-1}$ during cruises 9801 and 9807 respectively, which represented 7 times the average ingestion by Salpa fusiformis in 9807 and up to twenty times its ingestion in 9801. On the following cruise (9810) $S$. fusiformis ingested on average almost 100 times more than Thalia spp.

Requirements of daily PP for Thalia spp. and Salpa fusiformis combined were highly variable. In cruises with PP measurements, mean estimated carbon requirements (Method 1) were highest in $9810\left(107 \% \mathrm{~d}^{-1}\right)$, followed by 9807 $\left(31 \% \mathrm{~d}^{-1}\right)$, and lowest in 9904 and 9908 $\left(2 \% \mathrm{~d}^{-1}\right)$. However, excluding stations where the carbon ingestion was higher than $150 \% \mathrm{~d}^{-1}$ (Table 4) means would be 19 and $40 \%$ respectively. The extreme value of $664 \% \mathrm{~d}^{-1}$ of PP at station 120.50 (9810) may be related to the presence of abundant large (>11 mm) aggregates of $S$. fusiformis, while at the remaining stations salp aggregates attained a maximum size of $10 \mathrm{~mm}$. Low abundance of Thalia spp. and S. fusiformis was observed in April and August 1999, both periods characterized by elevated primary productivity (Table 4 ). Only a few stations surpassed 250 ind $\mathrm{m}^{-2}$ and the PP requirement in these cases was lower than $10 \% \mathrm{~d}^{-1}$.

Estimates of grazing considering integrated phytoplankton biomass (i.e. the amount of chlorophyll consumed in equivalent carbon units) resulted in lower values than for carbon ingestion from PP, though the pattern remained similar (Table 4). Apart from a few stations, values were typically $<10 \%$.

Carbon ingestion estimated from clearance rates of salps (Method 2) yielded values much lower than grazing estimated from weight-specific carbon demand 
Table 2. Salp species present in the IMECOCAL cruises (numbering represents year and month of cruise). X: present; -: not present

\begin{tabular}{|c|c|c|c|c|c|c|c|c|c|}
\hline \multirow{2}{*}{ Species } & \multicolumn{2}{|c|}{ — Winter —— } & \multirow{2}{*}{$\begin{array}{c}\text { Spring } \\
9904\end{array}$} & \multicolumn{2}{|c|}{-Summer- } & \multirow[b]{2}{*}{9710} & \multicolumn{2}{|c|}{-Autumn } & \multirow[b]{2}{*}{0010} \\
\hline & 9801 & 9901 & & 9807 & 9908 & & 9810 & 9910 & \\
\hline Cyclosalpa affinis & - & $\mathrm{X}$ & - & - & - & - & - & $\mathrm{X}$ & $\mathrm{X}$ \\
\hline Cyclosalpa bakeri & $\mathrm{X}$ & $\mathrm{X}$ & - & $\mathrm{X}$ & $\mathrm{X}$ & $\mathrm{X}$ & $\mathrm{X}$ & $\mathrm{X}$ & $\mathrm{X}$ \\
\hline Cyclosalpa polae & $\mathrm{X}$ & - & - & $\mathrm{X}$ & - & - & $\mathrm{X}$ & - & - \\
\hline Cyclosalpa sewelli & - & - & - & - & - & $\mathrm{X}$ & - & $\mathrm{X}$ & $\mathrm{X}$ \\
\hline Cyclosalpa quadriluminis & $\mathrm{X}$ & - & - & - & - & $\mathrm{X}$ & - & $\mathrm{X}$ & - \\
\hline Cyclosalpa strongylenteron & $\mathrm{X}$ & - & - & - & - & - & - & - & - \\
\hline Helicosalpa virgula & - & - & - & - & - & $\mathrm{X}$ & - & - & - \\
\hline Salpa aspera ${ }^{\mathrm{a}}$ & $\mathrm{X}$ & $\mathrm{X}$ & - & $\mathrm{X}$ & $\mathrm{X}$ & - & $\mathrm{X}$ & $\mathrm{X}$ & - \\
\hline Salpa cylindrica & $\mathrm{X}$ & - & $\mathrm{X}$ & $\mathrm{X}$ & - & $\mathrm{X}$ & $\mathrm{X}$ & - & $\mathrm{X}$ \\
\hline Salpa fusiformis & $\mathrm{X}$ & $\mathrm{X}$ & - & $\mathrm{X}$ & $\mathrm{X}$ & $\mathrm{X}$ & $\mathrm{X}$ & $\mathrm{X}$ & $\mathrm{X}$ \\
\hline Salpa maxima & $\mathrm{X}$ & - & - & - & - & - & - & - & $\mathrm{X}$ \\
\hline Salpa younti & - & - & - & - & - & - & - & - & $\mathrm{X}$ \\
\hline Ritteriella amboinensis & $\mathrm{X}$ & - & - & - & - & - & - & - & - \\
\hline Ritteriella picteti & $\mathrm{X}$ & - & - & $\mathrm{X}$ & $\mathrm{X}$ & $\mathrm{X}$ & $\mathrm{X}$ & $\mathrm{X}$ & $\mathrm{X}$ \\
\hline Ritteriella retracta & $\mathrm{X}$ & $\mathrm{X}$ & - & $\mathrm{X}$ & - & - & - & $\mathrm{X}$ & - \\
\hline Thalia cicar ${ }^{\mathrm{b}}$ & $\mathrm{X}$ & $\mathrm{X}$ & - & $\mathrm{X}$ & - & $\mathrm{X}$ & $\mathrm{X}$ & - & $\mathrm{X}$ \\
\hline Thalia democratica & $\mathrm{X}$ & $\mathrm{X}$ & $\mathrm{X}$ & $\mathrm{X}$ & $\mathrm{X}$ & $\mathrm{X}$ & $\mathrm{X}$ & $\mathrm{X}$ & $\mathrm{X}$ \\
\hline Thalia orientalis $^{\mathrm{b}}$ & $\mathrm{X}$ & $\mathrm{X}$ & $\mathrm{X}$ & $\mathrm{X}$ & $\mathrm{X}$ & $\mathrm{X}$ & $\mathrm{X}$ & $\mathrm{X}$ & $\mathrm{X}$ \\
\hline Thalia rhomboides ${ }^{\mathrm{b}}$ & $\mathrm{X}$ & - & - & $\mathrm{X}$ & - & $\mathrm{X}$ & - & $\mathrm{X}$ & $\mathrm{X}$ \\
\hline Pegea bicaudata & - & - & - & $\mathrm{X}$ & - & - & - & - & - \\
\hline Pegea confoederata & - & $\mathrm{X}^{\mathrm{c}}$ & - & - & $\mathrm{X}^{\mathrm{c}}$ & - & - & $\mathrm{X}$ & - \\
\hline Iasis zonaria & $\mathrm{X}$ & $\mathrm{X}$ & $\mathrm{X}$ & $\mathrm{X}$ & $\mathrm{X}$ & $\mathrm{X}$ & $\mathrm{X}$ & $\mathrm{X}$ & - \\
\hline Brooksia rostrata & - & - & - & - & - & - & $\mathrm{X}$ & - & - \\
\hline Ihlea punctata & $\mathrm{X}$ & $\mathrm{X}$ & $\mathrm{X}$ & $\mathrm{X}$ & $\mathrm{X}$ & $\mathrm{X}$ & $\mathrm{X}$ & - & - \\
\hline Traustedtia multitentaculata & - & - & - & - & - & - & - & - & $\mathrm{X}$ \\
\hline Total & 17 & 11 & 5 & 14 & 9 & 13 & 12 & 13 & 13 \\
\hline \multicolumn{10}{|c|}{$\begin{array}{l}\text { a Salpa fusiformis in Berner (1967) } \\
{ }^{\mathrm{b}} \text { Thalia democratica in Berner (1967) } \\
{ }^{\mathrm{c}} \text { Pegea sp. }\end{array}$} \\
\hline
\end{tabular}

(Method 1). Overall, higher ingestion estimates were associated with high salp biomass, particularly when Salpa fusiformis was abundant (Cruises 9810 and 9901). Only in some of the shallower coastal stations did ingestion estimated by both approaches give similar results. On average, ingestion rates estimated from daily rations were 3 times (9904) to 39 (9801) times higher than those estimated from clearance rates (Table 4).

Defecation rate estimates applied to Salpa fusiformis biomass in Cruise 9810 (14 to $2046 \mathrm{mg} \mathrm{C} \mathrm{m}^{-2}$ ) yielded daily fecal carbon fluxes from 4 to $609 \mathrm{mg} \mathrm{C} \mathrm{m}^{-2} \mathrm{~d}^{-1}$ (Table 4). On Cruise 9901 the estimated fecal fluxes were 17 to $206 \mathrm{mg} \mathrm{C} \mathrm{m}^{-2} \mathrm{~d}^{-1}$ in northern $\mathrm{BC}$, while in

Table 3. Spearman correlation coefficients (r), probability level (p) and sample size (n) for correlations of abundance of total salps, Thalia spp., and Salpa fusiformis correlated with environmental variables. Coefficients in bold: $\alpha<0.01$

\begin{tabular}{|c|c|c|c|c|c|}
\hline & $\begin{array}{l}\text { Temperature } \\
\text { at } 10 \mathrm{~m}\left({ }^{\circ} \mathrm{C}\right)\end{array}$ & $\begin{array}{l}\text { Salinity } \\
\text { at } 10 \mathrm{~m}\end{array}$ & $\begin{array}{l}\text { Density gradient } \\
\quad(0-100 \mathrm{~m})\end{array}$ & $\begin{array}{c}\text { Surface } \\
\text { chlorophyll a }\end{array}$ & $\begin{array}{c}\text { Integrated chlorophyl } \\
\quad a(0-150 \mathrm{~m})\end{array}$ \\
\hline \multicolumn{6}{|c|}{ Total salps } \\
\hline $\mathrm{r}$ & 0.18 & 0.24 & -0.12 & 0.02 & -0.10 \\
\hline $\mathrm{p}$ & $<0.01$ & $<0.01$ & 0.02 & 0.72 & 0.04 \\
\hline $\mathrm{n}$ & 432 & 431 & 366 & 402 & 388 \\
\hline \multicolumn{6}{|c|}{ Thalia spp. } \\
\hline $\mathrm{r}$ & 0.28 & 0.45 & -0.12 & 0.05 & -0.20 \\
\hline $\mathrm{p}$ & $<0.01$ & $<0.01$ & 0.06 & 0.41 & $<0.01$ \\
\hline $\mathrm{n}$ & 310 & 309 & 261 & 283 & 269 \\
\hline \multicolumn{6}{|c|}{ Salpa fusiformis } \\
\hline $\mathrm{r}$ & 0.13 & 0.15 & -0.10 & -0.09 & -0.15 \\
\hline $\mathrm{p}$ & 0.02 & $<0.01$ & 0.09 & 0.14 & 0.02 \\
\hline $\mathrm{n}$ & 310 & 309 & 261 & 283 & 269 \\
\hline
\end{tabular}




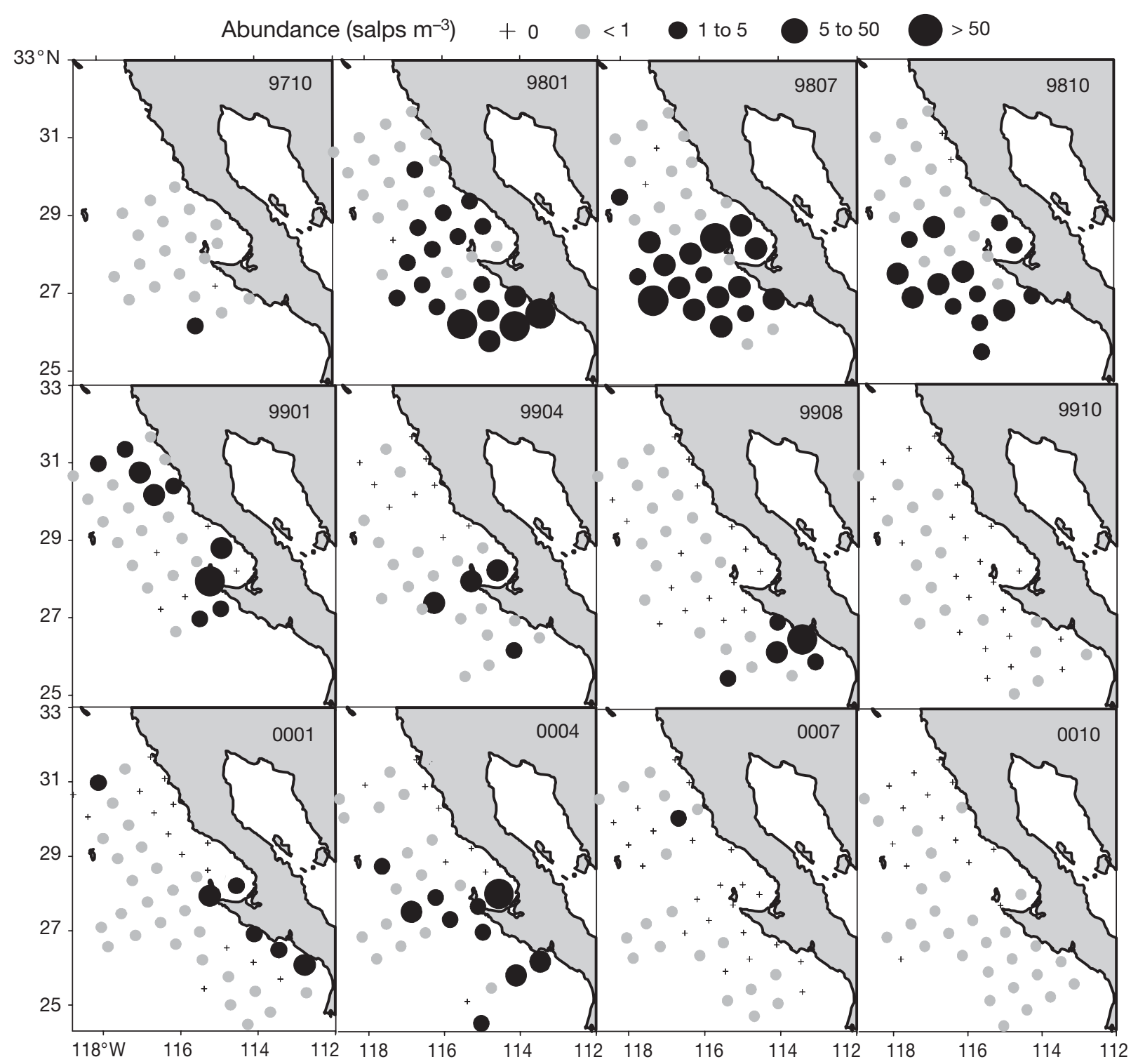

Fig. 6. Distribution of all salps during quarterly IMECOCAL cruises (nos. in panels: year and month of cruise), 1997-2000

the remaining cruises, low biomass of this species resulted in fecal carbon production lower than $21 \mathrm{mg} \mathrm{C}$ $\mathrm{m}^{-2} \mathrm{~d}^{-1}$. Thalia swarms in our study yielded high fecal carbon production rates up to $86 \mathrm{mg} \mathrm{C} \mathrm{m}^{-2} \mathrm{~d}^{-1}$ and $45 \mathrm{mg} \mathrm{C} \mathrm{m}{ }^{-2} \mathrm{~d}^{-1}$ during Cruises 9807 and 9801 respectively, decreasing to fecal fluxes $<10 \mathrm{mg} \mathrm{C} \mathrm{m}^{-2} \mathrm{~d}^{-1}$ following El Niño cruises.

\section{DISCUSSION}

\section{Salp composition and the ENSO cycle}

Appreciable changes in water mass characteristics occurred in the study area from late 1997 through 2000, associated with the development of the strong El
Niño 1997-1998 and the rapid transition to La Niña 1998-1999. According to Strub \& James (2002), 2 pulses of anomalously high sea surface height propagated from the equator toward mid-latitudes during spring and summer 1997, and autumn and winter 1997-1998. IMECOCAL Cruise 9710 took place when the second pulse reached the study area, although the El Niño signal had already propagated to northern latitudes earlier in 1997 (Durazo \& Baumgartner 2002, Lynn \& Bograd 2002, Strub \& James 2002). During this period, warmer and saltier waters were present in the upper $600 \mathrm{~m}$ as a result of the expansion and shoaling of the poleward CU and the Coastal Countercurrent (Durazo \& Baumgartner 2002). Maximum temperature and salinity anomalies ( $9^{\circ} \mathrm{C}$ and 0.8 , respectively) were observed in the upper layer (50 to $100 \mathrm{~m}$ ) in win- 


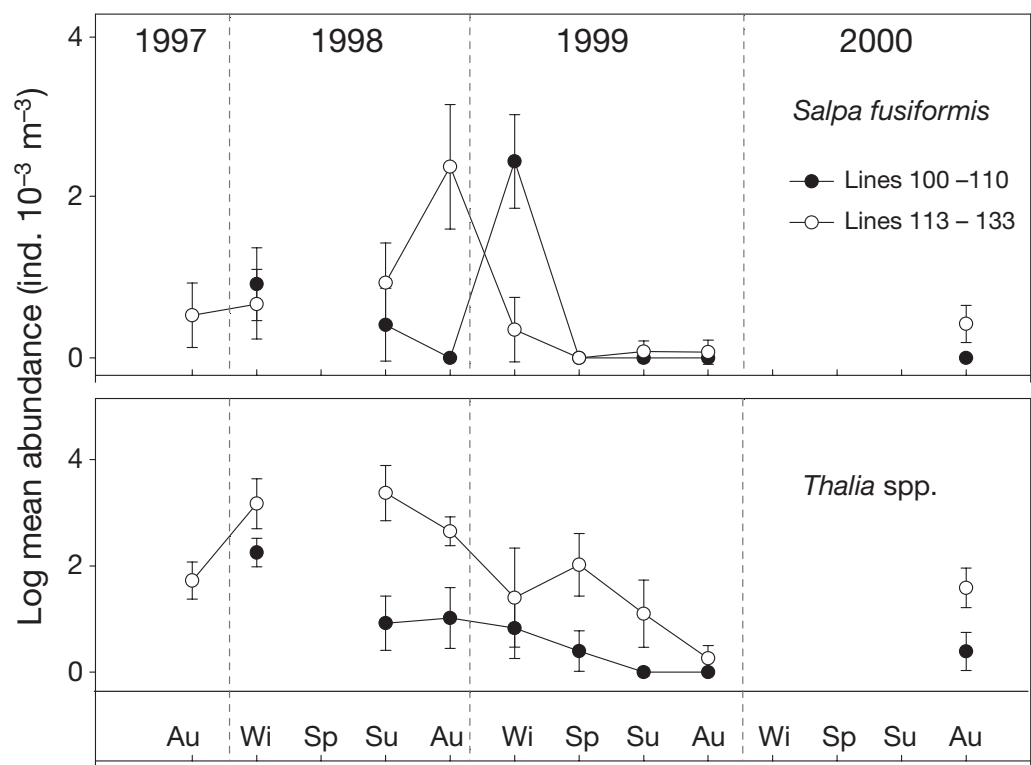

Fig. 7. Salpa fusiformis and Thalia spp. Regional mean and 95\% CI of abundance for northern BC (Lines 100 to 110) and central BC (Lines 113 to 133). Data were $\log (x+1)$ transformed. Au: autumn; Wi: winter; Sp: spring; Su: summer

ter 1998, but had almost disappeared by summer 1998 . Further transition to La Niña conditions was indicated by negative temperature and salinity anomalies, due to a marked presence of the cold and less saline California Current waters reaching the area from the $\mathrm{N}$.

These rapid and pronounced changes in oceanographic conditions produced changes in the salp assemblage, both in abundance and composition. Dense aggregations, particularly of the species complex of Thalia, were frequent in the warm phase (September 1997 to January 1998) and during transition to La Niña (July to October 1998). However, only in the warm phase (January 1998) were intrusions of Thalia orientalis detected in the more northerly region sampled. This suggests propagation of this species (and also T.rhomboides) by the subtropical water coming from the W during El Niño (Durazo \& Baumgartner 2002). T. democratica and Thalia cicar were more representative of late El Niño and the transitional phase, but never reached the high abundance $T$. orientalis reached in 1998. La Niña conditions affected the presence of the latter species in the area, mainly in October 1999 when temperatures were $2{ }^{\circ} \mathrm{C}$ below the longterm mean. In that cruise no swarms occurred and salps were essentially restricted to offshore stations.

Apart from Thalia rhomboides and T. cicar, several species that were present in January 1998 and were absent 1 yr later are known to be associated with warm waters (Yount 1954, Van Soest 1998). This pattern occurred in Salpa cylindrica, Cyclosalpa polae, C. strongylenteron and Ritteriella amboinensis (Table 2).
Fluctuations in salp abundance corresponded mainly to Thalia spp., which comprised $>90 \%$ of salps in all cruises, with the exception of October 1999. Three Thalia species identified in the present study ( $T$. democratica, $T$. orientalis, and T. rhomboides), were elevated by van Soest (1972) to the species rank, but had in previous studies been considered 'forms' of $T$. democratica (see Berner 1967). Changes in abundance of the 3 species (Fig. 10) suggested a temporal succession from T. rhomboides associated with warmer temperature, $T$. orientalis continually present but peaking in the early transition conditions, followed by T. democratica in October 1998. The other species of the genus, T. cicar, was restricted to the central $\mathrm{BC}$ region and attained peak abundance in July 1998, as did $T$. orientalis, but was absent for most of the cool period.

The dominant species in terms of abundance was Thalia orientalis, only surpassed by Salpa fusiformis in terms of biomass during the transition and the beginning of La Niña. The presence of these species, together with elevated abundance of chaetognaths, was responsible for relatively high zooplankton displacement volumes during the El Niño peak from October 1997 to January 1998 (Lavaniegos et al. 2002). Unlike more northerly regions in the CCS, this El Niño-related increase in zooplankton biomass off $\mathrm{BC}$ coincided with moderate blooms of phytoplankton off central $\mathrm{BC}$, as detected by direct measurements and satellite remote sensing (Kahru \& Mitchell 2000, Lavaniegos et al. 2002).

Central Baja was generally richer in salps than the more northerly region, both at coastal and at oceanic stations. This regional distribution explains in part the overall lack of correlation between total salp abundance and chlorophyll. The negative correlation between Thalia spp. and integrated chlorophyll was probably related to the high increase of phytoplankton biomass following El Niño when fewer salps were present. The estimates of grazing potential imply that salp grazing was not usually sufficient to cause this inverse relationship. Though salps typically occur in oligotrophic offshore waters and seldom reach the coast, the presence of Thalia swarms at coastal stations may be related to the ability of some salps to position themselves in the water column above or below the chlorophyll maximum in order to avoid high particle concentrations (cf. Harbison et al. 1986) at stations rich in phytoplankton (Paffenhöfer et al. 1995, Zeldis et al. 1995, Gibbons 1997). 


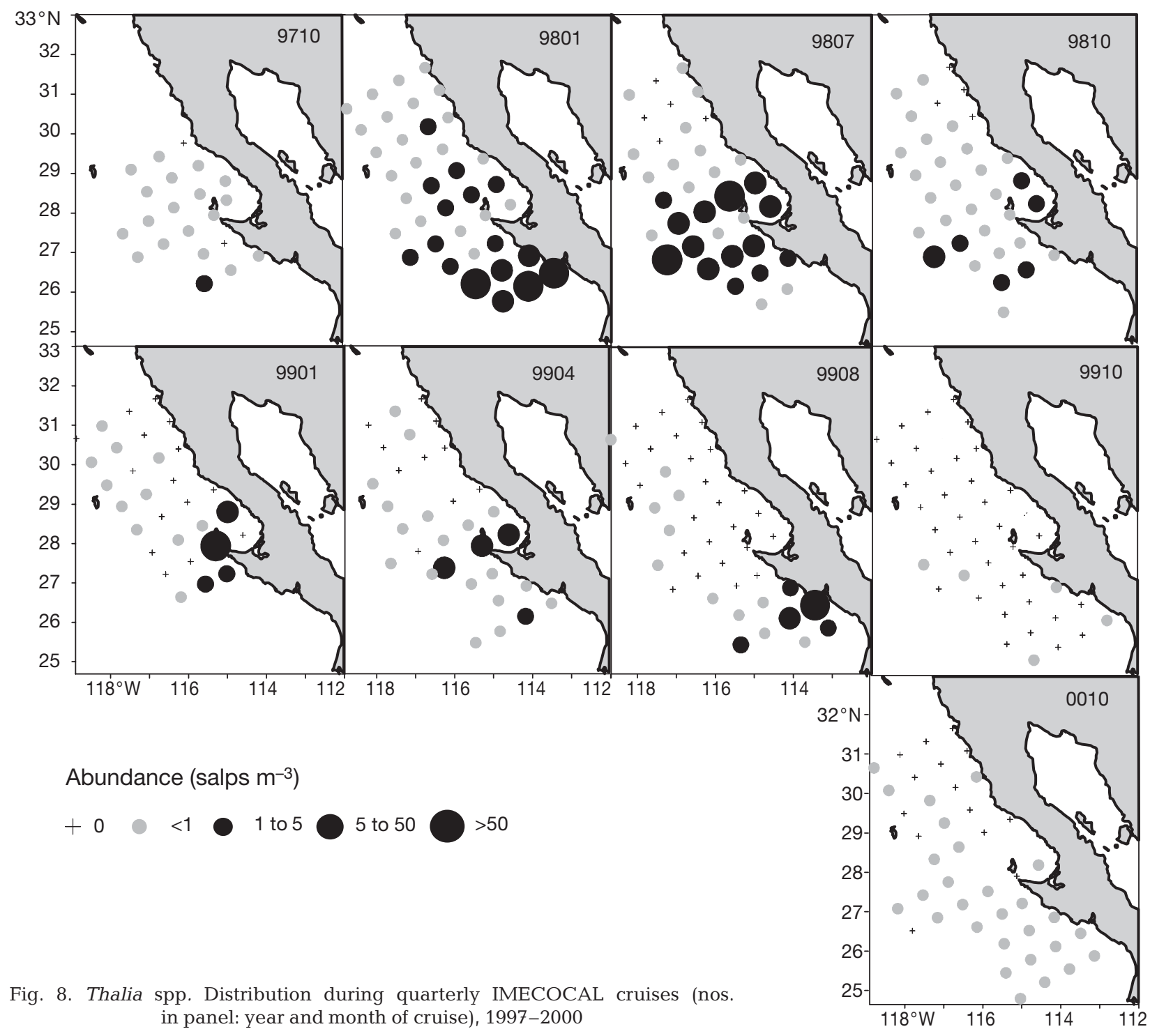

The second most abundant species, Salpa fusiformis, was present during El Niño 1997-1998, though maximum densities were observed in the transition to cool conditions near Punta Eugenia, switching to the northern and inshore stations in January 1999 (Fig. 9). In the earlier El Niño 1958-1959, S. fusiformis was almost absent in this area (Berner 1967) and further N, while it showed high abundance off Southern California during El Niño 1982-1983 (Lavaniegos \& Ohman 2003).

Salps have not been particularly useful as water mass indicators because of their cosmopolitan distribution. Thalia democratica and Salpa fusiformis can be found from $40^{\circ} \mathrm{N}$ to $40^{\circ} \mathrm{S}$. Nonetheless, several authors have described the appearance of a high abundance of Thalia associated with the advection of warmer offshore waters into coastal regions (Paffenhöfer et al. 1995) or within high temperature eddies (Gibbons
1997). Lavaniegos \& Ohman (2003) found differences in the long-term variability of different salp species in the southern California Current region related to the latitudinal extent (and thus geographic origins) of each species, with the more northerly species showing lower abundances during a $21 \mathrm{yr}$ warm period. In the present study we found a positive correlation between Thalia spp. abundance and warmer and saltier surface waters, and a similar, but weaker relationship when all the other salp species observed were also included (total salps, Table 3 ). Warmer, saltier waters also coincided with the presence of a deeper thermocline (Durazo \& Baumgartner 2002). These hydrographic features are partly associated with the intrusion of subtropical waters from the SW during the peak of El Niño (see Fig. 12 in Durazo \& Baumgartner 2002). According to Berner (1957) and Blackburn (1979), T. democratica 


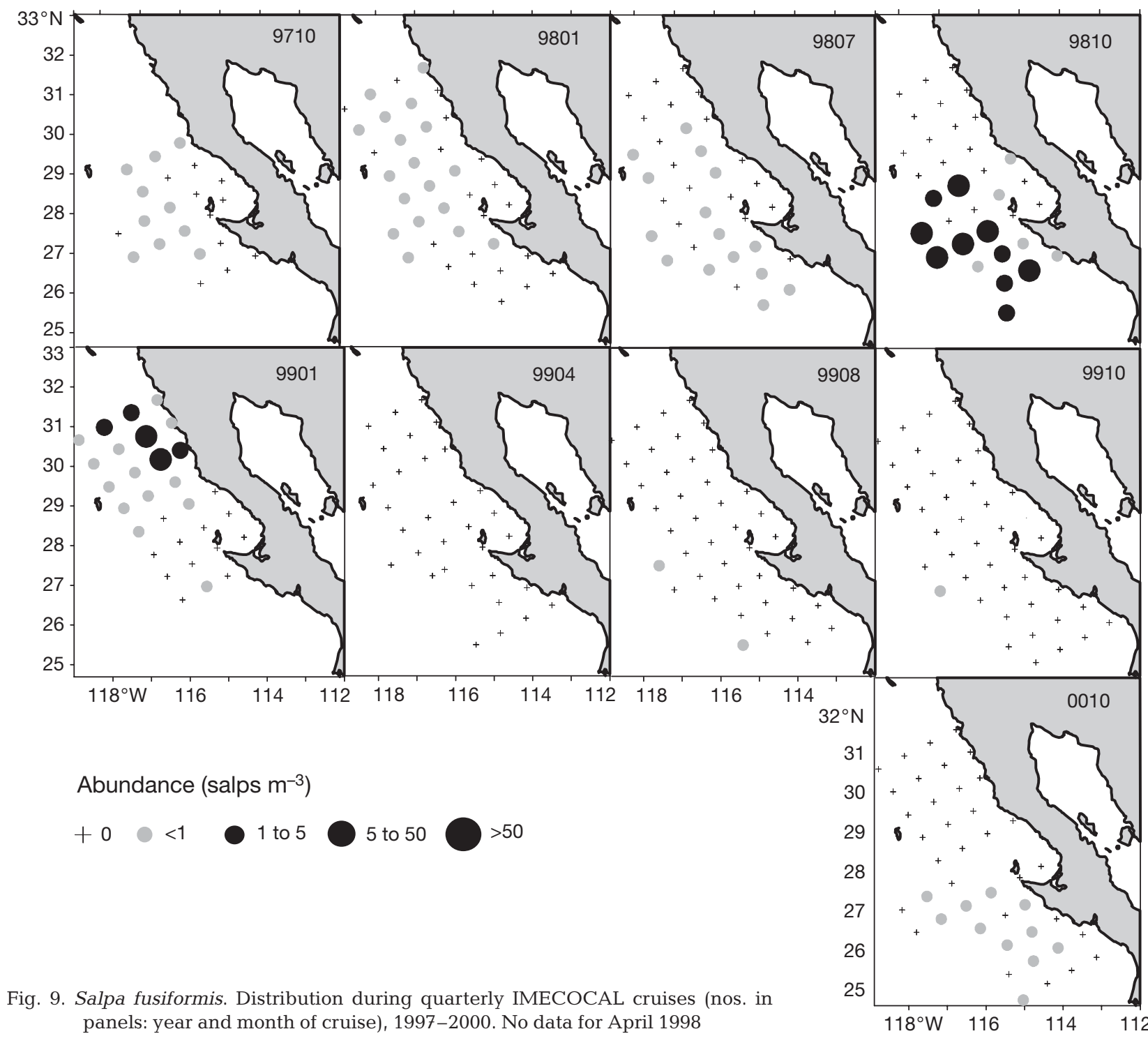

is a species of Central Pacific waters and enters the CCS from the W. This suggests that Thalia spp. may be favored by El Niño conditions in the southernmost part of the CCS. Thalia species may be seeded into the area from the SSW and if favorable conditions are present, they rapidly reproduce and form swarms. High surface temperatures, the mesotrophic conditions during the first part of 1998, together with a stratified water column may have produced suitable conditions for these species. Charts of the distribution of $T$. democratica from Berner (1967) suggest that there was a similar pattern during El Niño 1957-1958 when they were consistently present at densities of up to 5 ind $\mathrm{m}^{-3}$ off northern and central BC, while salps were barely present in northern areas of the CCS. González et al. (2000b) also report the appearance of T. democratica during El Niño 1997- 1998 off Chile, replacing dense aggregations of $S$. fusiformis which reached peak abundance before El Niño.

The differences we observed among Thalia species in response to environmental conditions also suggest the existence of some interspecific ecological differences. $T$. orientalis abundance increased during El Niño and was determined more often at coastal stations than T. democratica, which recovered from mid-1998. T. rhomboides and T. cicar appeared only in the1997-1998 cruises at southern stations, the former swarming only in January 1998. These dynamics suggest that $T$. orientalis, and to a lesser degree T. democratica may be more eurythermic and able to develop in a wider spectrum of environmental conditions. These apparent differences may explain in part the unsuccessful attempts of previous studies to relate Thalia abundance to physical conditions in the CCS (Berner 1957, Blackburn 1979). The presence of 


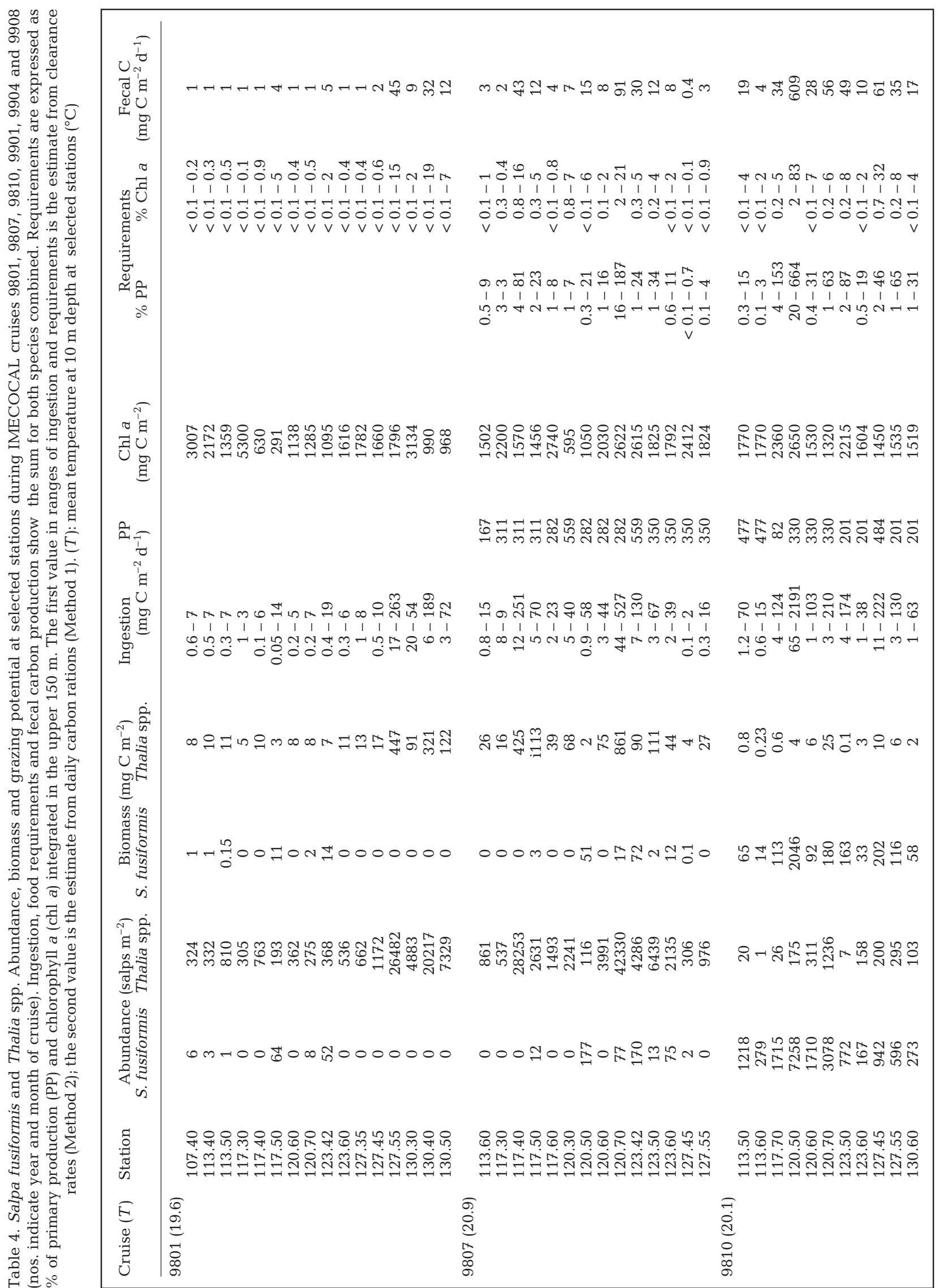




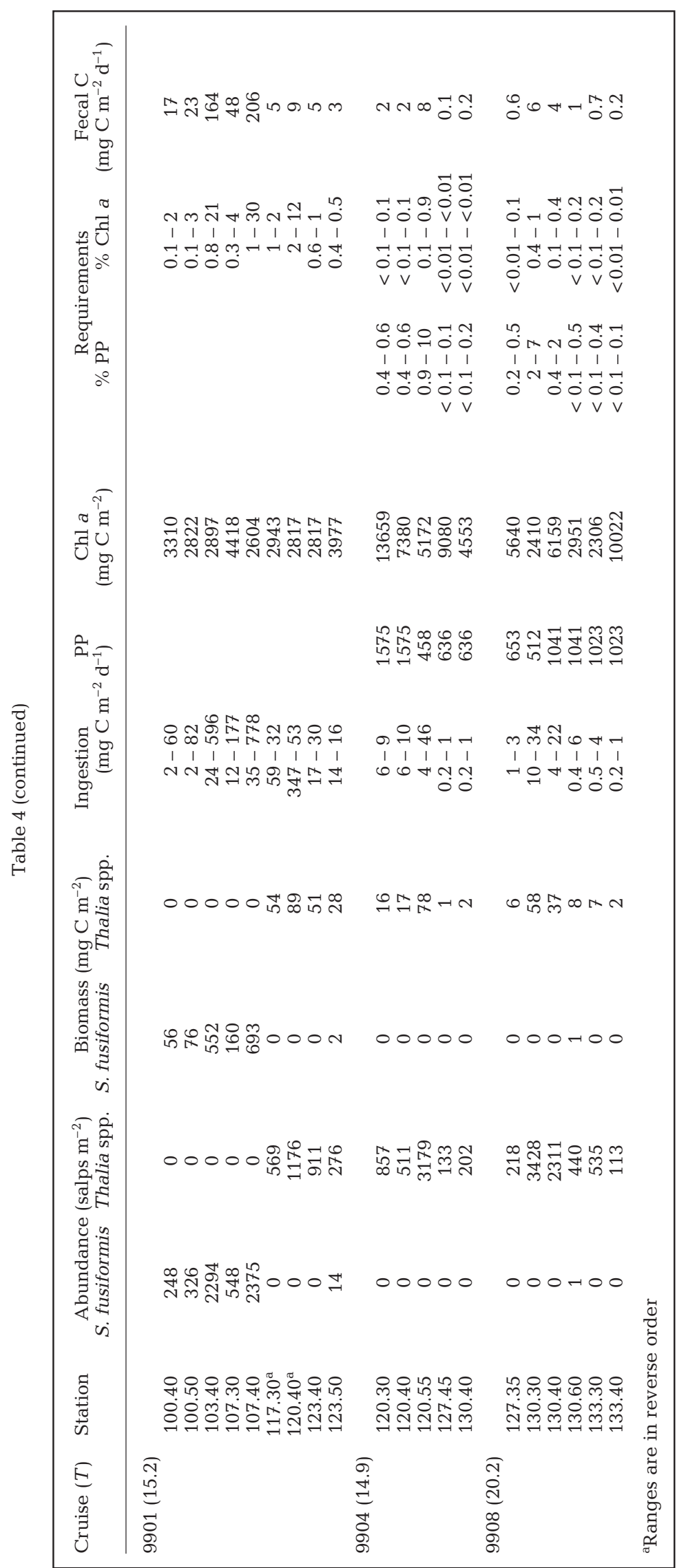

T. rhomboides, which is commonly present in tropical waters and was conspicuous during the second and stronger peak of El Niño 1997-1998, could be an indicator of El Niño conditions in this sector of the CC. This needs to be tested with data from other El Niño events in the area.

\section{Grazing impact}

We first estimated the grazing impact as the fraction of the phytoplankton stock and production removed by aggregation of salps, based on published daily carbon requirements where animals were fed high quality food in the laboratory (Method 1). The results indicated that swarms of Thalia spp. and Salpa fusiformis could ingest from $<1$ to more than $100 \%$ of the daily primary production, with average requirements generally higher in 1998 than in 1999.

Grazing estimates based on clearance rate (Method 2) were even more conservative than those obtained by the first approach, since salps appeared capable of clearing only a small fraction of their resident water (in this case, the total water filtered during each sampling tow). However, if it is assumed that salps, mainly Thalia species, are restricted to a narrower depth stratum than the $200 \mathrm{~m}$ used for calculations in the present study, the proportion of cleared water would increase. Furthermore, since we assumed that salps remove a fraction of particles in the water equal to the fraction of water filtered, then ingestion would be underestimated if, in fact, salps feed in strata of higher food concentration. Also, no corrections were made for shrinkage in length due to preservation, which is around $10 \%$ for T. democratica and $20 \%$ for Salpa fusiformis (Madin et al. 1981, Heron et al. 1988, Nishikawa \& Terazaki 1996). This shrinkage would result in an underestimate of volumes filtered by salps of about $30 \%$ for Thalia and between 50 and $80 \%$ for $S$. fusiformis (taking into account aggregate and solitary forms, respectively). If the same corrections due to shrinkage were applied to carbon biomass estimates, values in Table 4 would increase around $20 \%$ for Thalia and around 65 and $45 \%$ for $S$. fusiformis aggregates and solitaries, respectively. Temperature corrections for grazing rates were not attempted either. Temperature effects on clearance rates are not so evident for Thalia, although temperature influences filtering rate and ingestion of $S$. fusiformi (Andersen 1986). Average environmental (10 m depth) temperatures at selected stations $\left(15\right.$ to $21^{\circ} \mathrm{C}$, 


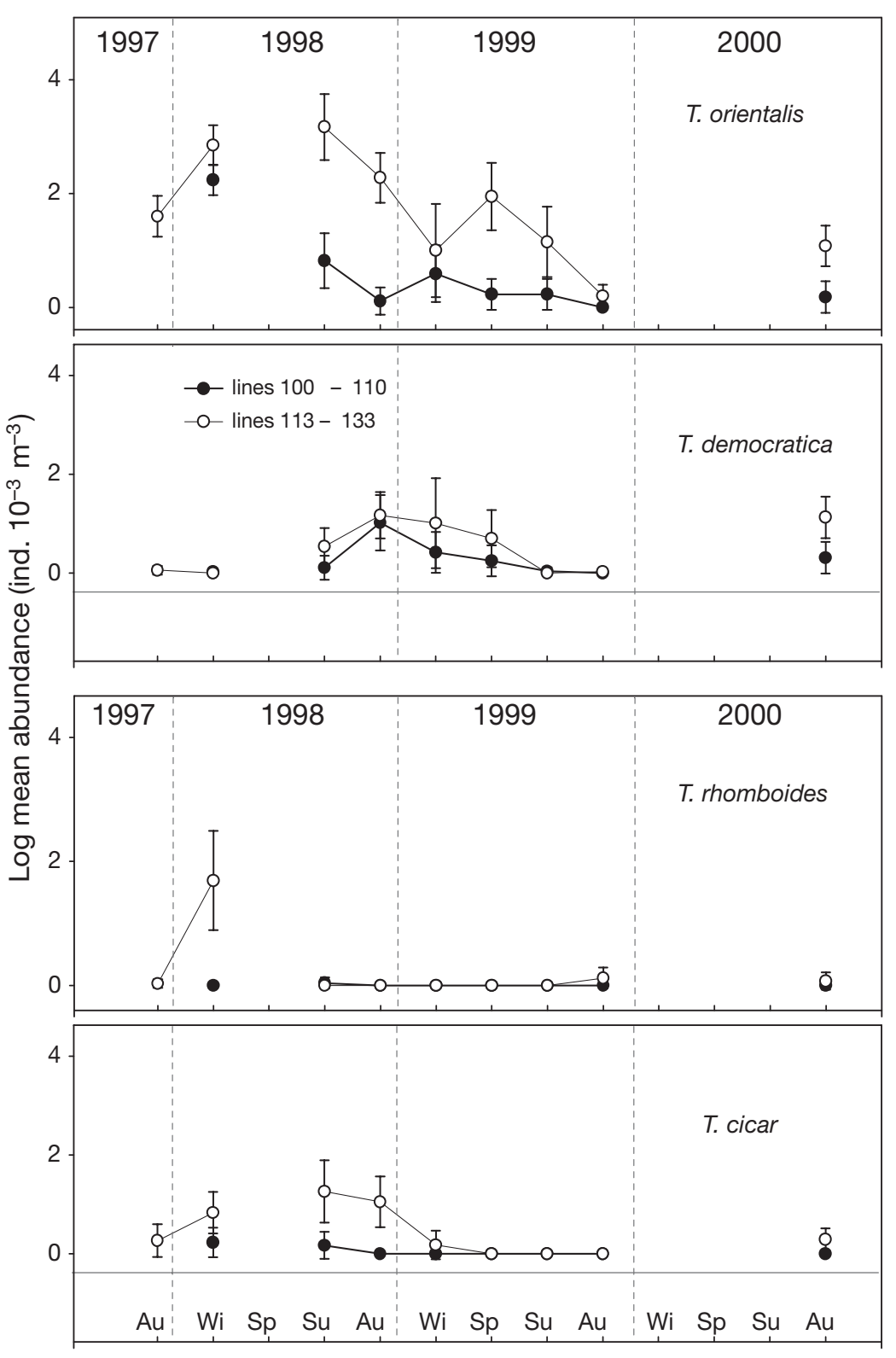

Fig. 10. Thalia orientalis, T. democratica, T. rhomboides, and T. cicar. Regional mean abundance and 95\% CI, for northern BC (Lines 100 to 110) and central BC (Lines 113 to 133). Data were $\log (x+1)$-transformed. Au: autumn; Wi: winter; Sp: spring; Su: summer

Table 4) were similar to temperatures used in laboratory studies, except during Cruise 9810 for $S$. fusiformis and Cruise 9904 for Thalia. In the latter 2 cases, the rates would be somewhat different but our overall conclusions would not change. The gut pigment method is considered to give results closest to in situ feeding rates when compared to alternative methods (Madin \& Kremer 1995), but this approach was not feasible here. In any case, our estimates can be considered only within the range of the likely average ingestion and potential impact.
Though salps rarely dominate the zooplankton in coastal eutrophic areas, blooms of Thalia spp. and Salpa fusiformis have been observed in this study as in other upwelling systems (Fortier et al. 1994). Salps are thought to only partially reduce phytoplankton biomass in coastal environments (Zeldis et al. 1995), while they can consume a high fraction of phytoplankton biomass and production from the euphotic zone in slope and oceanic waters (González et al. 2000a, Huskin et al. 2003). In the present study, in oligotrophic conditions during El Niño (or mesotrophic conditions in the area) salps, where abundant in swarms, may consume a significant fraction of the daily production. In more eutrophic conditions (La Niña cruises in 1999), salps consumed only a minor fraction of the production and chlorophyll standing stock. In the moderate El Niño 2002, dense aggregations of the large salp Pegea socia were recorded in the area, in addition to a major contribution of doliolids to the gelatinous herbivorous assemblage (Durazo et al. 2005); however, grazing estimates are not available from this study.

Increased vertical fluxes can be an important consequence of salp swarming. Mean defecation rates of Salpa fusiformis applied to the highest biomass of this species in Cruise 9810 (2046

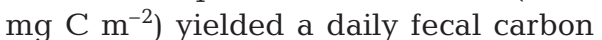
flux of $609 \mathrm{mg} \mathrm{C} \mathrm{m}^{-2} \mathrm{~d}^{-1}$. This estimate exceeds daily primary production, hence would not be sustainable over time. On Cruise 9901 the biomass of S. fusiformis ranged from 56 to $693 \mathrm{mg} \mathrm{C}$ $\mathrm{m}^{-2}$, and the estimated fecal fluxes were 17 to $206 \mathrm{mg} \mathrm{C} \mathrm{m}^{-2} \mathrm{~d}^{-1}$. These fluxes were higher than those estimated in the Humboldt Current by González et al. (2000a) during pre El Niño conditions in January 1997 (2.8 to $30 \mathrm{mg} \mathrm{C} \mathrm{m}^{-2} \mathrm{~d}^{-1}$ for coastal and oceanic regions, respectively), where $S$. fusiformis was less abundant (53 to 570 individuals $\mathrm{m}^{-2}$ respectively). Our estimate of fecal production is within the rates estimated for other species of the genus Salpa in the North Pacific. Iseki (1981) reported a carbon flux of $10.5 \mathrm{mg} \mathrm{C} \mathrm{m}^{-2} \mathrm{~d}^{-1}$ from fecal pellets of Salpa sp. settled in sediment traps, while Matsueda et al. (1986) determined a flux of 6.7 to $23 \mathrm{mg} \mathrm{C} \mathrm{m}^{-2} \mathrm{~d}^{-1}$ after a salp swarm. Carbon fluxes from dense aggregations of Salpa aspera (6500 ind. $\mathrm{m}^{-2}$ or 
$909 \mathrm{mg} \mathrm{C} \mathrm{m}^{-2}$ ) were estimated between 8.5 and $137 \mathrm{mg}$ $\mathrm{C} \mathrm{m}^{-2} \mathrm{~d}^{-1}$ in the western North Atlantic (Wiebe et al. 1979). Landry et al. (1994) reported that mesozooplankton grazing on $44 \%$ of PP resulted in a carbon flux of $470 \mathrm{mg} \mathrm{C} \mathrm{m}^{-2} \mathrm{~d}^{-1}$ during a winter cruise when small tunicates, dominated by Thalia, were particularly abundant in the Southern California Bight. No estimates of defecation rate exist for $T$. democratica, but a rate of $10 \%$ of body weight applied to Thalia swarms in our study yielded pellet production rates of $<1$ to $86 \mathrm{mg} \mathrm{C} \mathrm{m}^{-2} \mathrm{~d}^{-1}$ for abundances of 306 and 42330 ind. $\mathrm{m}^{-2}$ respectively (Table 4 ).

It has been shown that sizes of prey and consumers are important concepts in determining the particulate flux in pelagic food webs (Michaels \& Silver 1988, Fortier et al. 1994). Therefore, a shift in the size structure of the zooplankton community is expected to cause changes in the partitioning of primary production and the export to deeper layers. During El Niño 1997-1998 several structural changes in the zooplankton community were described off BC (Lavaniegos et al. 2002, Jimenez-Perez \& Lavaniegos 2004). The El Niño surveys were characterized by the presence of small copepods of tropical and subtropical affinity. While copepod abundance declined $11 \%$ from autumn 1997 to autumn 1998, the relative abundance of gelatinous herbivores, and particularly salps, increased during the same period and decreased afterwards.

Small salps produce smaller fecal pellets with low sinking rates, which can be degraded rapidly or serve as a food source for coprophages, retarding the vertical flux of particles (Pomeroy \& Deibel 1980, Small et al. 1983). On the other hand, swarms of Salpa fusiformis, a larger migrant salp which produce larger pellets with faster settling rates than Thalia feces (Andersen 1998) were present during transitional conditions towards La Niña and may have contributed more to the downward transport of particulate organic matter. Similarly, González et al. (2000a) found that phytoplankton consumed by metazooplankton and exported as feces under non El Niño conditions varied significantly, depending on the presence of swarms of this species.

In conclusion, our results suggest that the introduction and proliferation of salps off Central BC may be favored during El Niño. The presence of warmer and saltier waters, a deepened thermocline, and reduced mesoscale features were associated with an increase in abundance of Thalia. The disruption of these conditions resulted in the proliferation of Salpa fusiformis, which swarmed for a short period, while isolated patches of Thalia persisted in the southern part of the study area. The grazing impact estimated for these 2 dominant salps indicated that during oligotrophic to mesotrophic conditions (in El Niño cruises) salps could consume a significant proportion of primary production and pro- duce a substantial fecal carbon. During conditions of higher primary productivity, salps appeared to ingest a relatively small fraction of primary production.

Acknowledgements. We thank the staff of the IMECOCAL cruises, without whose work this study would not have been possible. Funding was provided by CONACYT (grants G0041-T9607, G35326-T, and 017PÑ-1297), the Inter-American Institute for Global Change Research (Grant ISP 2-124), CICESE (projects 6212 and 6548), US GLOBEC (grant OCE 01-103000 from NSF and NOAA to M.D.O.), and the California Current Ecosystem LTER site. C.M.H. was funded by a scholarship from Secretaria de Relaciones Exteriores of Mexico and a supplementary grant from the CICESE, and the CONACYT G35326-T project. GLOBEC contribution No. 310. The previous version of the manuscript benefited from helpful comments given by 2 anonymous reviewers.

\section{LITERATURE CITED}

Aguirre-Hernández E, Gaxiola-Castro G, Nájera-Martínez S, Baumgartner T, Kahru M, Mitchell BG (2004). Phytoplankton absorption, photosynthetic parameters, and primary production off BC: summer and autumn 1998. DeepSea Res II 51:799-816

Andersen V (1985) Filtration and ingestion rates of Salpa fusiformis Cuvier (Tunicata: Thaliacea): effects of size, individual weight and algal concentration. J Exp Mar Biol Ecol 87:13-29

Andersen V (1986) Effects of temperature on the filtration rate and percentage of assimilation of Salpa fusiformis Cuvier (Tunicata: Thaliacea). Hydrobiologia 137:135-140

Andersen V (1998) Salp and pyrosomid blooms and their importance in biogeochemical cycles. In: Bone Q (ed) The biology of pelagic tunicates. Oxford University Press, Oxford, p 125-138

Berner LD (1957) Studies on the Thaliacea of the temperate Northeast Pacific Ocean. PhD dissertation, University of California, Los Angeles

Berner LD (1967) Distributional Atlas of Thaliacea in the California Current region. Calif Coop Ocean Fish Investig Atlas 8:1-322

Blackburn M (1979) Thaliacea of the California Curent region: relations to temperature, chlorophyll, currents, and upwelling. Calif Coop Ocean Fish Investig Rep 20:184-214

Bograd SJ, Lynn RJ (2001) Physical-biological coupling in the California Current during the 1997-99 El Niño-La Niña cycle. Geophys Res Lett 28:275-278

Cetta CM, Madin LP, Kremer P (1986) Respiration and excretion by oceanic salps. Mar Biol 91:529-537

Chavez PF, Pennington JT, Castro CG, Ryan JP and 6 others (2002) Biological and chemical consequences of the 1997-1998 El Niño in central California waters. Prog Oceanogr 54:205-232

Deibel D (1982) Laboratory-measured grazing and ingestion rates of the salp, Thalia democratica Forskal, and the doliolid Dolioletta gegenbauri Uljanin (Tunicata, Thaliacea). J Plankton Res 4:189-201

Durazo R, Baumgartner TR (2002) Evolution of oceanographic conditions off BC: 1997-1999. Prog Oceanogr 54:7-31

Durazo R, Gaxiola-Castro G, Lavaniegos B, Castro-Valdez R, Gómez-Valdés J, Mascarenhas Jr. A (2005) Oceanographic conditions of the west BC coast 2002-2003: El Niño and subartic water enhancement. Cienc Mar 31(3) 537-552 
Eppley RW (1968) An incubation method for estimating the carbon content of phytoplankton in natural samples. Limnol Oceanogr 13:574-582

Fortier L, Le Fèvre J, Legendre L (1994) Export of biogenic carbon to fish and to the deep ocean: the role of large planktonic microphages. J Plankton Res 16:809-839

Gibbons MJ (1997) Vertical distribution and feeding of Thalia democratica on the Agulhas Bank during march 1994. J Mar Biol Assoc UK 77:493-505

Godeaux JEA (1998) The relationships and systematic of the Thaliacea, with keys for identification. In: Bone Q (ed) The biology of pelagic tunicates. Oxford University Press, Oxford, p 273-294

González HE, Ortiz VC, Sobarzo M (2000a) The role of faecal material in the particulate organic carbon flux in the northern Humboldt Current, Chile $\left(23^{\circ} \mathrm{S}\right)$, before and during the 1997-1998 El Niño. J Plankton Res 22:499-529

González HE, Sobarzo M, Figueroa D, Nöthig EM (2000b) Composition, biomass and potential grazing impact of the crustacean and pelagic tunicates in the northern Humboldt Current area off Chile: differences between El Niño and non-El Niño years. Mar Ecol Prog Ser 195: 201-220

Harbison GR, VL McAlister, RW Gilmer (1986) The response of the salp, Pegea confoederata, to high levels of particulate material: starvation in the midst of plenty. Limnol Oceanogr 31:371-382.

Heron AC, McWilliam PS, Dal-Pont G (1988) Length-weight relation in the salp Thalia democratica and potential of salps as a source of food. Mar Ecol Prog Ser 42:125-132

Hickey BM (1979) The California Current System-hypotheses and facts. Prog Oceanogr 8:191-279

Hopcroft RR, Clarke C, Chavez FP (2002) Copepod communities in Monterey Bay during the 1997-1999 El Niño and La Niña. Prog Oceanogr 54:251-264

Huskin I, Elices MJ, Anadón, R (2003) Salp distribution and grazing in a saline intrusion off NW Spain. J Mar Syst 42: $1-11$

Huyer A (1983) Coastal upwelling in the California Current System. Prog Oceanogr 12:259-284

Iseki K (1981) Particulate organic matter transport to the deep sea by salp fecal pellets. Mar Ecol Prog Ser 5:55-60

Jimenez-Pérez LC, Lavaniegos BE (2004) Changes in dominance of copepods off BC during the 1997-1999 El Niño and La Niña. Mar Ecol Prog Ser 277:147-165

Kahru M, Mitchell G (2000) Influence of the 1997-98 El Niño on the surface chlorophyll in the California Current. Geophys Res Lett 27:2937-2940

Landry MR, Lorenzen CJ, Peterson WK (1994) Mesozooplankton grazing in the southern California Bight. II. Grazing impact and particulate flux. Mar Ecol Prog Ser 115:73-85

Lavaniegos BE, Ohman MD (2003) Long-term changes in pelagic tunicates in the California Current. Deep-Sea Res 50:2473-2498

Lavaniegos BE, Jiménez-Pérez LC, Gaxiola-Castro G (2002) Plankton Response to El Niño 1997-1998 and La Niña 1999 in the southern region of the California Current. Prog Oceanogr 54:33-58

Linacre LP (2005) Community structure of euphausiids in the southern part of the California Current during October 1997 (El Niño) and October 1999 (La Niña). Calif Coop Ocean Fish Investig Rep 45:126-135

Lynn RJ, Simpson JJ (1987) The California Current system: the seasonal variability of physical characteristics. J Geophys Res 92:12947-12966

Lynn RJ, Bograd SJ (2002) Dynamic evolution of the 1997-1999 El Niño-La Niña cycle in the southern Califor- nia Current System. Prog Oceanogr 54:59-75

Lynn RJ, Bliss KA, Eber LE (1982) Vertical and horizontal distributions of seasonal mean temperature, salinity, sigma-t, stability, dynamic height, oxygen and oxygen saturation in the California Current, 1950-1978. Calif Coop Ocean Fish Investig Atlas 30:1-513

Mackas DL, Galbraith M (2002) Zooplankton community composition along the inner portion of Line P during the 1997-1998 El Niño event. Prog Oceanogr 54:423-437

Madin LP, Kremer P (1995) Determination of the filter feeding rates of salps (Tunicata, Thaliacea). ICES J Mar Sci 52: 583-595

Madin LP, Cetta CM, McAlister VL (1981) Elemental and biochemichal composition of salps (Tunicata, Thaliacea). Mar Biol 63:217-226

Matsueda H, Handa N, Inoue I, Takano H (1986) Ecological significance of salp fecal pellets collected by sediment traps in the eastern North Pacific. Mar Biol 91:421-431

Michaels AF, Silver MW (1988) Primary production, sinking fluxes and the microbial food web. Deep-Sea Res 35: 473-490

Mullin MM (1983) In situ measurement of filtering rates of the salp, Thalia democratica, on phytoplankton and bacteria. J Plankton Res 5:279-288

Nishikawa J, Terazaki M (1996) Tissue shrinkage of two gelatinous zooplankton, Thalia democratica and Dolioletta gegenbauri (Tunicata: Thaliacea) in preservative. Bull Plankton Soc Jpn 43(1):1-7

Paffenhöfer GA, Atkinson P, Lee TN, Verity PG, Bulluck LR III (1995) Distribution and abundance of thaliaceans and copepods off the southeastern USA during winter. Contin Shelf Res 15:255-280

Peterson WT, Keister JE Feinberg LR (2002) The effects of the 1997-99 El Niño/La Niña events on hydrography and zooplankton off the central Oregon coast. Prog Oceanogr 54: 381-398

Pomeroy LR, Deibel D (1980) Aggregation of organic matter by pelagic tunicates. Limnol Oceanogr 24:643-652

Small LF, Fowler SW, Moore SA, La Rosa J (1983) Dissolved and fecal pellet carbon and nitrogen release by zooplankton in tropical waters. Deep-Sea Res 30:1199-1220

Sosa-Ávalos R (2002) Estimación de la producción primaria frente a BC por sensores remotos. PhD dissertation, Centro de Investigación Científica y Educación Superior de Ensenada, Ensenada

Strub PT, James C (2002) Altimeter-derived surface circulation in the large-scale NE Pacific Gyres: Part 2. 1997-1998 El Niño anomalies. Prog Oceanogr 53:185-214

Van Soest RMW (1972) The genus Thalia Blumenbach, 1798 (Tunicata, Thaliacea), with descriptions of two new species. Beaufortia 20:193-212

Van Soest RWM (1998) The cladistic biogeography of salps and pyrosomas In: Bone Q (ed.) The biology of pelagic tunicates. Oxford University Press, Oxford, p 231-249

Venrick EL, Hayward TL (1984) Determining chlorophyll on the 1984 CalCOFI surveys. Calif Coop Ocean Fish Investig Rep 10:221-231

Yount JL (1954) The taxonomy of the Salpidae (Tunicata) of the central Pacific Ocean. Pac Sci 8:276-330

Wiebe PH, Madin LP, Haury LR, Harbison GR, Philibin LM (1979) Diel vertical migration by Salpa aspera and its potential for large-scale particulate organic matter transport to the deep-sea. Mar Biol 53:249-255

Zeldis JR, Davis CS, James MR, Ballara SL, Booth WE, Chang FH (1995) Salp grazing: effects on phytoplankton abundance, vertical distribution and taxonomic composition in a coastal habitat. Mar Ecol Prog Ser 126:267-283

Submitted: June 25, 2005; Accepted: December 14, 2005

Proofs received from author(s): July 3, 2006 